\title{
Runs on Money Market Mutual Funds*
}

\author{
Lawrence Schmidt ${ }^{\dagger}$ \\ University of California, San Diego University of California, San Diego \\ Russ Wermers ${ }^{\S}$ \\ University of Maryland at College Park
}

22 October 2012

\begin{abstract}
This paper studies daily investor flows to and from each money market mutual fund during the period surrounding and including the money fund crisis of September 2008. We focus on the determinants of flows in the prime money fund category to shed light on the covariates of money fund runs, since this category was, by far, the most heavily impacted by the money fund crisis. We find that outflows during the crisis period of September 17-19 are concentrated among a small fraction of funds having certain characteristics. Institutional investors focused their run-like behavior on large funds that were part of a complex having large amounts of institutional money funds (as a fraction of all money funds). In addition, such investors were more likely to run from funds with higher yields, lower expense ratios, and higher prior flow volatility, indicating that "hot money" chased yields, but selectively ran from higher-yield funds that were more vulnerable. Our analysis also suggests that prime retail money funds exhibited many of the same behaviors as institutional funds, although at a much slower and more drawnout pace. Our paper provides a framework that is useful in understanding potential further regulatory responses to the crisis.
\end{abstract}

Key words: Money market mutual funds; financial crisis, money fund crisis, breaking the buck, quantile regression.

JEL codes:

\footnotetext{
${ }^{*}$ We thank participants at Finlawmetrics 2010: Fifth International Conference on Financial Regulation and Supervision (Central Banking, Regulation, and Supervision, Bocconi University, Milan, June 2010); the Paul Woolley Centre 2010 Conference at University of Technology, Sydney (especially Philip Gharghori of Monash University, the discussant); the CAREFIN Conference (September 2010, Milan); the Conference on Systemic Risk and Data Issues in Washington, D.C. (September 2011, a joint conference of Carnegie Mellon, NYU, University of California, Berkeley, and University of Maryland; special thanks to Chester Spatt, the discussant); the University of Notre Dame Conference on Current Topics in Financial Regulation (June, 2012, Washington, D.C.; especially Woodrow Johnson, the discussant); the Western Finance Association Annual Meetings (2012, Las Vegas); and seminar participants at the University of Illinois at Chicago. We gratefully acknowledge financial support for this research from the Center for Financial Policy at the Smith School of the University of Maryland and from the Paul Woolley Centre for the Study of Capital Market Dysfunctionality at the University of Technology, Sydney.

${ }^{\dagger}$ Department of Economics, UCSD, 9500 Gilman Drive, La Jolla CA 92093-0508. lschmidt@ucsd.edu

${ }^{\ddagger}$ Rady School of Management, University of California, San Diego, 9500 Gilman Drive, La Jolla CA 92093-0553. atimmermann@ucsd.edu.

${ }^{\S}$ Smith School of Business, University of Maryland, College Park, MD 20850. rwermers@rhsmith.umd.edu.
} 


\section{Introduction}

Bank runs have long been a subject of academic and regulatory interest. There are two primary and competing theories of how bank runs propagate. One theory (Diamond and Dybvig, 1983) postulates that bank runs, driven by depositors who fear the actions of other investors, can occur as an equilibrium phenomenon - even in banks that would remain fully solvent if no investors withdrew. Once the (self-fulfilling) run starts, all bank customers seek the return of their deposits as quickly as possible, since each customer's withdrawal imposes a negative externality on all other investors (due to the reduction in bank liquidity that results).

Another theory is that runs may be rationally driven by information: customers seek to discern which banks are solvent and which are not (Jacklin and Bhattacharya, 1988). According to this theory, only insolvent banks (or banks thought to be insolvent on the basis of public information) face runs. These two theories have quite different implications for the potential for bank runs as well as for optimal regulatory responses to this threat.

In the eyes of some investors, money market funds have become a substitute for bank deposits. Retail investors often keep much of their liquid assets in money market funds to pay bills, purchase consumer goods, or settle securities trades, and to transfer money back and forth to these funds as liquidity is needed on (if necessary) a daily basis. ${ }^{1}$ Although investments in money market funds are not guaranteed (as fund prospectuses and marketing literature clearly state), some investors seem to believe that implicit guarantees exist, either from the management company or from the U.S. Government. In addition, money funds have become a major short-term financing alternative for corporations, who may be able to obtain cheaper financing by selling their short-term debt to these funds, compared to bank loans or other financing methods. And, financial institutions, including regulated banks, often invest in money market mutual funds to gain a higher yield with their excess overnight liquidity.

In this paper, we study a run on money market mutual funds that developed during September 2008. Money market funds, as we explain, have certain characteristics in common with banks, but

\footnotetext{
${ }^{1}$ Some market observers have referred to money market mutual funds as "shadow banks," although without any explicit guarantee of capital safety.
} 
also have significant differences. Owing to these similarities and differences, we believe that the episode of September 2008 presents a unique opportunity to add perspective to the literature on bank runs. This money market run is unique, relative to commercial bank runs, because data is available on the types of investors who withdrew money each day, as well as the characteristics of fund and management companies that suffered runs. Our main goal in this paper is to explore the determinants of this episode, such as the institutional characteristics of different money market funds, their portfolio holdings, and their investors, with a view to shedding light on the mechanisms by which runs propagate.

During the days that followed the failure of Lehman Brothers on September 14, 2008, a single money market fund that held Lehman debt securities, the Reserve Primary Fund, "broke the buck," that is, marked the net asset value of the fund below the $\$ 1$ per share that investors normally expect. This was the first time that a major money market fund had failed to return principal of $\$ 1.00$ per share to investors on demand. ${ }^{2}$ The event sparked vast outflows from the Reserve Primary Fund. Within a few days, the panic spread to other money funds. Prime money market funds - those that hold investment grade money market instruments, such as commercial paper, repurchase agreements, bank certificates of deposit, and Eurodollar deposits - suffered outflows totaling roughly $\$ 300$ billion, even though many of these funds held little or no Lehman Brothers debt. In contrast, government-only money market funds - those that invest primarily or exclusively in Treasury and Agency securities - experienced vast inflows.

On September 19, 2008, the U.S. Treasury announced an optional program to "insure the holdings of any publicly offered eligible money market mutual fund - both retail and institutionalthat pays a fee to participate in the program." This insurance was available to money funds with a shadow NAV of at least $\$ 0.995$ - ensuring that the NAV would be restored to $\$ 1$ - only for assets invested prior to September 19, 2008. On the same day, the Federal Reserve instituted programs to help provide liquidity to money market funds and the money markets more generally. Within a few weeks, large "panic-driven" outflows from prime money market funds diminished and, ultimately,

\footnotetext{
${ }^{2}$ In 1994, a single small money market fund failed. However, that money market fund was closely held by a group of banks. Consequently, its failure had little implication for other money market funds and their investors. The incidents of September 2008 were different: the Reserve Primary Fund was a very large fund, and its investors included a broad range of retail and institutional customers.
} 
ceased.

We study the daily flows in money market mutual funds during this crisis period in an effort to determine whether they were sparked by a widespread withdrawal of all investors (as modeled by Diamond and Dybvig), or whether withdrawals were more information-based (as in Jacklin and Bhattacharya). For instance, we wish to determine who initiated runs (institutional vs. individual investors), as well as the timing of their withdrawals (e.g., whether they developed over several days). Further, we wish to observe the reaction of the fund management companies, to determine how they met the liquidations. Finally, we wish to determine the features of funds that were susceptible to large-scale withdrawals, using fund size, complex characteristics, or portfolio weighted average yield.

We first show that outflows of money market mutual funds during the crisis occurred in a very heterogeneous way. Investors in a small minority of funds having certain characteristics exhibited the bulk of run-like behavior, while investors in most other funds did not exhibit such behavior. Next, we provide insights about the types of funds with run behavior. First, prime institutional funds exhibited much larger persistence in outflows than retail funds, although retail investors also exhibited some run-like behavior. Next, we find that funds that were larger, had a lower expense ratio, were a member of a complex with a larger proportion of institutional money (in money market funds), had higher lagged flow standard deviation, and had a higher portfolio-weighted promised yield exhibited greater outflows during the crisis week of $2008 .^{3}$ These findings are consistent with run-like behavior predominantly occurring among more-sophisticated institutions ("hot money") that focused their trades on certain types of funds.

Specifically, hot money chased yields in larger, low-expense funds prior to the crisis, and considered the potential of a complex to "backstop" its institutional funds when deciding on whether to move their money during the crisis. More exposed complexes exhibited a larger tendency to experience investor run-like behavior.

We then implement both panel OLS models and quantile regression models to more formally study the covariates of investor runs during the crisis. The quantile analysis accounts for changes

\footnotetext{
${ }^{3}$ A mutual fund "complex" is a family of mutual funds sponsored by a single provider who typically also manages the group of funds. For example, some of the largest mutual fund complexes are those operated by Fidelity, Vanguard, Federated, and JP Morgan Chase.
} 
in the dynamics of fund flows during the crisis of September-October 2008 and for cross-sectional heterogeneity in the effect of fund and investor characteristics on fund flows. Our focus on shifts in the dynamics of fund flows is motivated by evidence indicating that fund flows behaved very differently during and around the money market fund crisis triggered by the events leading up to the failure of Lehman.

We focus on cross-sectional heterogeneity in fund flows for a few reasons. First, welfare and policy implications may differ depending on whether outflows are evenly distributed across funds. Imagine that there are 10 funds with identical observable characteristics and we observe a $5 \%$ net outflow on a given day. If all funds have the same $5 \%$ outflow, each may be able to absorb the shock with little impact-funds likely have plenty of liquid securities on hand to meet redemptions. On the other hand, if 8 funds have no outflows and 2 funds face $25 \%$ redemptions, these funds are likely to be in grave trouble. Large redemptions may force them to sell less liquid assets at fire sale prices, potentially leading to the "liquidity spiral" discussed in Brunnermeier and Pedersen (2009). Second, when examining the theoretical literature on bank runs and liquidity, a number of models feature multiple equilibria. Even in those where equilibria are unique, small changes in fundamentals can lead to large changes in outcomes. As such, we might have reason to expect substantial heterogeneity in the fund flow distribution. Third, quantile regression is known to have a variety of desirable robustness properties. OLS regressions can be much more sensitive to leverage points and outliers in the data, relative to quantile regressions. Given that we are looking at outflows during a crisis period with a number of large outflows, this property seems desirable.

Our results from estimations of these models indicate that withdrawals occurred unevenly across funds and fund complexes during the September 2008 crisis. Funds that cater to institutional investors, which are the most sophisticated and informed investors, were hardest hit. Certain fund complexes were harder hit than others, suggesting that the events following September 15, 2008 were not purely panic driven. Instead, investors were, to some extent, discerning. Thus, during September 2008, investor flows from money market funds seem to have been driven both by strategic externalities (a la Diamond-Dybvig) and information (a la Jacklin and Bhattacharya). ${ }^{4}$ Our paper

\footnotetext{
${ }^{4}$ This seems consistent with steps taken by regulators and fund managers in an effort to stem the crisis. For example, on the regulatory side, the Treasury's approach of guaranteeing money market funds makes sense to the extent that investor flows were driven by externalities: if investors simply panicked, a federal government guarantee
} 
provides some guidance to regulators and to fund complexes in forming strategies to avert another such money market mutual fund crisis.

Our paper proceeds as follows. Section 2 provides a background on money market mutual funds, and reviews the events of the crisis. In section 3, we provide a short literature review on bank runs. Section 4 discusses our dataset, while section 5 discusses our methodology. Section 6 presents our main empirical results, while section 7 briefly presents some robustness tests. We conclude in section 8 .

\section{Background}

Banks and money market funds are similar in some respects (e.g., the presumption of dollarin-dollar-out) but quite different in others (e.g. vastly different regulatory structures, including disclosure requirements). Thus, money funds provide a unique laboratory to study the mechanics of runs. In addition, money fund data provide a unique opportunity, since we can observe daily flows from investor types in each money market fund-institutional versus retail, as well as some information on the particular type of institutional or retail investor (e.g. defined benefit pension plans versus bank trust accounts). Further, we can observe characteristics of the management company running the money fund. Such data is not available to researchers for banks and their deposit accounts.

In principle, money market funds are much like other mutual funds. For instance, like other mutual funds, they are regulated under the Investment Company Act of 1940 and its various amendments (henceforth, ICA). However, they operate under a special provision of the ICA, Rule 2a-7, which lets them value investor shares at the "amortized cost" of assets - an accounting-based rather than a market-based principle - that is, shares are valued at the purchase price of securities minus computed premium or discount, amortized over the securities' remaining life. ${ }^{5}$ This provision of the ICA allows money funds to maintain essentially a constant $\$ 1.00$ per share net asset value.

would likely dampen fears. The programs the Federal Reserve put in place to provide liquidity would also help, allowing money market funds that were otherwise stable to meet vast redemptions by nervous investors. On the fund manager side, many funds addressed information issues by publishing fund portfolio holdings more often and in greater detail than required by the SEC. Thus, in many cases, investors were able to tell on a daily basis what securities their money market funds were holding.

${ }^{5}$ This is also how bonds are valued on accounting balance sheets of corporations. 
For investors, this has many advantages. It allows retail investors to use their money market funds for transactions purposes, such as paying bills and settling securities trades. They are also able to tie their money market funds to bank products, such as checking accounts, ATMs, and credit cards. A constant $\$ 1.00 \mathrm{NAV}$ allows many kinds of institutions (e.g. state and local governments) to hold their liquid balances in money market funds, since they are restricted from investing in variable NAV products. And, for both retail and institutional investors, a constant $\$ 1.00 \mathrm{NAV}$ vastly simplifies tax accounting by eliminating the need to track the capital gains and losses that arise with a long-term mutual fund.

However, valuing money funds at amortized cost creates the potential for a run, because the fund's price per share (which is based on a book value) can diverge from the market value of the fund's underlying portfolio securities. Like banks, money market funds seek to offer highly liquid liabilities, while holding less liquid assets. To be sure, this liquidity mismatch is much less extreme for money market funds, but still raises the possibility that a money market fund might become liquidity-constrained, unable to meet redemption requests, despite holding highly liquid assets. ${ }^{6}$

These risks have been controlled differently in banks and money funds. Banks are required to maintain capital, and depositors are insured, but banks may generally hold highly illiquid assets (e.g. 30-year mortgages), hold assets that may be lower-rated or difficult to rate or price, and may employ leverage. Money market funds, in contrast, under Rule 2a-7, must hold only highly liquid, high quality assets, and generally may not use leverage. ${ }^{7}$ The Securities and Exchange Commission (SEC) and others have long recognized the potential exposure of money market funds; the SEC has recently tightened the provisions under which money market funds operate, and are currently considering further regulations to control this potential exposure. ${ }^{8}$

\footnotetext{
${ }^{6}$ This issue can also arise with long-term mutual funds. Mutual funds are required by law to offer investors the ability to redeem their shares on a daily basis at the fund's net asset value per share. It is at least theoretically possible that requests for redemptions could outstrip a fund's ability to liquidate its underlying portfolio in order to satisfy those redemptions. This possibility is more meaningful for bond mutual funds, such as during a financial crisis if liquidity were to dry up in certain fixed income instruments (e.g., high yield bonds).

${ }^{7}$ Over the years, the provisions of Rule 2a-7 have been tightened to further reduce systemic risks (see Collins and Mack).

${ }^{8}$ Specifically, amendments to Rule 2a-7, effective on May 5, 2010, have imposed several new requirements on money market mutual funds. These include, among other things: (??) requiring that a fund hold 10\% of its portfolio value in securities that may be easily liquidated within one day, and $30 \%$ that may be easily liquidated within one week; (2) reduce the maximum weighted average maturity from 90 to 60 days, and (??) require fund management to "know your clients" to judge flow volatility, and to increase asset liquidity, if necessary. Among other things, the SEC is considering further requiring funds to convert to a floating NAV.
} 
Prior to September 2008, Rule 2a-7 had worked well to control risks. From the point at which Rule 2a-7 was first adopted by the SEC in 1983 to September 2008, a period during which hundreds of banks and thrifts failed, only a single money market fund had "broken the buck" (i.e. failed to return $\$ 1.00$ per share). Even that event went largely unnoticed, because the fund was small and held by a limited number of institutional investors (primarily banks). ${ }^{9}$ However, this changed on September 16, 2008, when the Reserve Primary Fund "broke the buck."10

Numerous traumatic economic events had occurred since August 2007, putting considerable pressure on money market funds, as investors sought liquidity. From August 2007 to August 2008, several unregulated liquidity pools used by institutional investors failed, both in the U.S. and elsewhere. This led to vast inflows to money market funds, as these institutional investors turned to the tighter regulatory provisions required of money market funds under Rule 2a-7.

Also, the federal government declined to assist a reeling Lehman Brothers, which failed on September 15, 2008. On September 16, 2008, one large money market fund, the Reserve Primary Fund, which held about $\$ 750$ million in commercial paper issued by Lehman Brothers, disclosed that it had broken the buck. Immediately, prime money market funds began to see vast outflows, which totaled over $\$ 300$ billion within a few days. ${ }^{11}$ With credit markets seizing up, prime money market funds struggled to sell securities to meet these redemptions.

On Friday, September 19, 2008, the U.S. Treasury offered a guarantee to money funds in exchange for an "insurance premium" payment. On that same day, the Federal Reserve announced The Asset-Backed Commercial Paper Money Market Mutual Fund Liquidity Facility to provide funding to U.S. depository institutions and bank holding companies to finance purchases of highquality asset-backed commercial paper (ABCP) from money market mutual funds under certain conditions. This program was set up to assist money funds holding such paper to meet redemption demands and to promote liquidity in the ABCP market and money markets more generally. This program began operations on September 22, 2008, and was closed on February 1, 2010.

\footnotetext{
${ }^{9}$ The Community Bankers US Government Fund broke the buck in 1994. It was an institutional fund, and paid investors 96 cents per share.

${ }^{10}$ It should be noted that there are several instances where the $\$ 1 \mathrm{NAV}$ would have been broken, had the fund advisor not intervened by injecting capital or buying poorly performing assets.

${ }^{11}$ There is some debate about this figure, as State Street apparently froze the assets of the Reserve Primary Fund after the exodus of about $\$ 10$ billion. The $\$ 300$ billion figure includes redemptions that were sent, but not honored by shareholders of this fund. Source: Pete Crane of Crane Data, LLC.
} 
In addition, in response to the growing difficulty of corporations in rolling over their short-term commercial paper, the Fed announced The Commercial Paper Funding Facility on October 7, 2008, followed by additional details on October 14, 2008. This program took effect on October 27, 2008, and was designed to provide credit to a special purpose vehicle that would purchase three-month commercial paper from U.S. issuers.

On October 21, 2008, the Federal Reserve announced another program, The Money Market Investor Funding Facility October 21, 2008, the Federal Reserve announced another program, The Money Market Investor Funding Facility (MMIFF). The MMIFF was a credit facility provided by the Federal Reserve to a series of special purpose vehicles established by the private sector. Each SPV was able purchase eligible money market instruments from eligible investors using financing from the MMIFF and from the issuance of asset-backed commercial paper (ABCP). Eligible Assets included certificates of deposit, bank notes and commercial paper with a remaining maturity of at least seven days and no more than 90 days.

In addition, the SEC took a number of actions, perhaps the most important of which was to allow money market funds to price their underlying securities at amortized cost at a point during the crisis when quotes on commercial paper were generally regarded as unreliable. ${ }^{12}$ Following these developments, investors continued to redeem shares from prime money market funds, but at a diminishing rate. By the end of October 2008, redemptions essentially ceased.

To illustrate, Figure 1 (top panel) shows daily changes in the net assets of the Reserve Primary fund during September 2008. Severe outflows began on September 13, 2008-perhaps due to some sophisticated investors anticipating that the fund's holdings of Lehman securities were in peril. By the end of September 2008, the Reserve Primary Fund had stemmed outflows. The bottom panel of Figure 1 shows flows for all six aggregate fund categories of funds over the same month. Clearly, prime institutional funds were most severely affected, with prime retail and tax-free funds also showing significant daily outflows.

In contrast, money market funds holding U.S. Government-backed securities (mainly Treasuries and agencies) experienced strong inflows, as investors sought the liquidity of the Treasury market

\footnotetext{
${ }^{12}$ This was an interesting development, especially since the SEC later proposed a floating NAV as a potential solution to runs on money market funds.
} 
as safety. Figure 2 shows, for government and prime money funds, the daily flows in billions of dollars. Note that the magnitude of the outflows in prime institutional funds is magnified, due to the large scale of these investments, relative to the outflows in prime retail funds.

\section{The Literature on Runs}

Several areas of the literature on bank runs are relevant for our study of runs on money market mutual funds. An early literature on bank runs, most notably Diamond and Dybvig (DD; 1983), model how a bank run can be an equilibrium outcome with bank deposits, in the absence of asymmetric information between banks and investors. In DD's equilibrium, investors think the bank is going to fail, and it becomes a self-fulfilling prophecy, that is, the bank would not fail if investors do not run.

Instead of attributing bank runs to such indiscriminate "animal spirits," Jacklin and Bhattacharya (1988) model information-based bank runs, which are driven by two-sided asymmetric information - the bank cannot observe the liquidity needs of the depositors, and depositors cannot observe the bank asset quality. The intermediate arrival of information about the quality of a bank's portfolio can trigger a run.

More recently, some papers use global games with regime shifts to study runs on banks. Angeletos, Hellwig, and Pavan (2007) analyze a setting in which regime changes occur as a result of the decision of a sufficiently large proportion of agents to attack the current (status quo) regime. They show that multiple equilibria can arise even after allowing agents to learn about the underlying fundamentals. While fundamentals have predictive information about the stability of the current equilibrium state, they generally do not determine the exact time of the breakdown.

Interestingly, conditional on the underlying fundamentals, an equilibrium can entail oscillations between periods of calm, where no traders attack the current state (e.g., exchange rate), versus periods of market distress, in which a regime change is a likely outcome.

Angeletos et al. (2007) show that the stability and multiplicity of equilibria are linked to the arrival of new private information. In the absence of any new information, an equilibrium exists in which an unsuccessful attack in the first period is followed by no regime shift in all subsequent 
periods. Conversely, the arrival of new private information makes future regime changes possible. Moreover, the equilibrium will, at any point in time, depend both on the amount of private and public information available, as well as on the history of how the equilibrium responded to attacks in the past. That is, after a failed attack, only a significant increase in the precision of private information signals will make future regime changes possible. ${ }^{13}$

These theories are relevant to our analysis of the money market mutual fund crisis, since money market funds escaped largely unscathed from the failure of Bear Stearns in April 2008. This suggests that a large shock to agents' information was required to explain the massive outflows from money market funds during September 2008 following the collapse of Lehmann.

In our setting, it is likely that some investors, e.g., hedge funds, are more informed than others, e.g., corporate retirement funds, about the liquidity of portfolio holdings and the tendency of other investors to run. It is broadly believed that, prior to the crisis of September 2008, there were investors with "smart money," who closely monitored the yields and stability of money market funds, while there were other investors with "dumb money," who did not. ${ }^{14}$

In a related study, Jank and Wedow (2010) study German money funds during the crisis. They find that German money funds competed for flows, which respond to past performance of funds, by investing in less liquid securities prior to the financial crisis. Funds that engaged in this riskshifting to the greatest degree suffered larger outflows during the crisis, i.e., investors appeared to understand the potential for runs in funds with less liquid holdings. Therefore, less liquid funds attract flows at the risk of developing an investor run if a market distortion occurs (such as the Lehman default)..$^{15}$

In another related study, Chen, Goldstein and Jiang (2010) document the presence of strategic

\footnotetext{
${ }^{13}$ Some models proposed in the literature also allow small shifts in fundamentals or in traders' information to have disproportionately large effects (nonlinearities) on equilibrium outcomes (e.g., Morris and Shin, 1998). This may not be a necessary consideration here, however, since the Lehmann bankruptcy by no measure was a "small" shock.

14 "Dumb money" can occur due to agency costs. For example, a hedge fund manager is compensated directly from fund profits, while a treasurer who oversees a corporate retirement plan may face much more limited compensation incentives. The hedge fund manager, therefore, is more likely to expend search costs to frequently gather information about each money market fund.

${ }^{15}$ It is interesting, also, in light of the recent call of many from the Securities and Exchange Commission for a conversion of U.S. money market mutual funds to a floating NAV standard, that the German money funds in the Jank and Wedow sample had floating NAVs. However, there is some debate about the definition of "money market funds" in Europe, since ultrashort bond funds are sometimes categorized as money market funds in Europe. The funds in the Jank and Wedow sample likely included what U.S. investors would consider ultrashort bond funds.
} 
complementarities investors in non-money market mutual funds. They explore whether the sensitivity of outflows to bad past performance is greater among illiquid funds, for which the strategic complementarities are greater, compared with more liquid funds, for which such effects are much smaller because redemption costs are much lower. They also explore whether funds dominated by large investors are less subject to runs induced by strategic complementarities because large investors will internalize the externalities induced by their withdrawals.

\section{Data and Initial Results}

We first describe our data and present some initial empirical results based on non-parametric analysis.

\subsection{Data}

Our data are derived from iMoneyNet (www.imoneynet.com). iMoneynet collects daily information for over 2,000 U.S. registered money market mutual funds that invest primarily in U.S. short-term, dollar-denominated debt obligations. These money funds are offered to retail as well as institutional investors. The iMoneyNet data consists of daily total net assets by share class, as well as data on the fund investment objective, fund family/adviser (i.e., "complex"), fund type (i.e. retail vs. institutional), portfolio average maturity, and asset breakdown. Our daily money fund dataset from iMoneyNet covers the period December 31, 2007 to June 30, 2009. We approximate daily fund share class flows as the daily change in share class assets (this ignores the negligible effect of the small daily dividends that money market funds declare). ${ }^{16}$

Table 1 shows the total net assets and number of shareholder accounts in these funds at the end of each year from 1990 to 2008. The total assets held in money market funds increases from almost $\$ 500$ billion at the end of 1990 to more than $\$ 3.8$ trillion at the end of 2008 , reflecting the huge increase in popularity of these funds among individuals and institutions. As of December 2008 , the total M2 money supply in the United States was $\$ 8.3$ trillion, of which $\$ 1.3$ trillion was

\footnotetext{
${ }^{16}$ Almost all money fund dividends are reinvested in the same money fund share class, so distributions (and their passive reinvestments) have a negligible effect on our estimates of flows.
} 
invested in retail share classes of money market mutual funds. ${ }^{17}$ Therefore, money market funds are a substantial share of liquid assets for individuals in the U.S. Note that, until the crisis of 2008, money market funds holding predominantly non-government securities dominated the asset value of the sample. During 2008, assets held in government money market funds nearly doubled to $\$ 1.45$ trillion. Note, also, that there were 38 million shareholder accounts as of December 2008, most of which were retail accounts. Therefore, a large cross-section of individuals in the U.S. hold assets in money market funds, indicating that any perceived instability of money funds may impact a large proportion of U.S. investors. In terms of assets, institutions own about two-thirds of money funds. Therefore, even outflows from a relatively small number of institutional accounts could impact money funds.

Table 2 explores the yearly number of money market mutual funds and the yearly number of shareclasses within each asset-class category. Note that the average number of shareclasses per fund has increased from slightly over one to almost three during the sample period. This trend indicates that the actions of one class of investors has a greater potential to affect other classes over time, such as institutions affecting individuals, and vice-versa.

Table 3 shows the net cash inflows, as well as a breakdown into sales and redemptions for each year from 1984 to 2008 . The table shows that flows into money market funds have been vastly increasing over the sample period, especially since about 1995. Note, also, the movement toward money funds during the market crisis of 2007 and 2008.

It is important to understand the characteristics of portfolio holdings of money funds to explore the liquidity and other risks that they carry. Table 4 shows that funds that focus on nongovernmental securities made a secular movement from commercial paper to bank CDs, repurchase agreements, and corporate notes over our sample period. Clearly, funds have become more diversified among asset classes, while retaining a weighted-average asset maturity of almost 50 days.

\footnotetext{
${ }^{17} \mathrm{M} 2$ consists of currency, traveler's checks, demand deposits, other checkable deposits, retail money market mutual funds, savings, and small time deposits. See www.federalreserve.gov/releases/h6/hist/h6hist1.txt for yearly values of M2 and www.ici.org for yearly retail money fund assets.
} 


\subsection{Data Analysis: Non-parametric Results}

To motivate our model-based analysis, we present summary graphical evidence of fund flow patterns around the money market fund crisis, and the extent of cross-sectional heterogeneity in such patterns during and around the time of the crisis.

\subsubsection{Heterogeneity in Outflows Across Funds}

Figure 2 shows sizeable aggregate outflows from our sample of prime money market funds during the crisis. However, it does not show to what extent all funds experienced similar outflows or whether, alternatively, a few outlier funds experienced disproportionate outflows. The degree of heterogeneity in fund outflows is important to address for several reasons. First, individual funds differ both in terms of the riskiness of their holdings and in terms of their investor characteristics, so understanding the distribution of these characteristics, and their impact on fund flows, is crucial prior to specifying our empirical models. Second, from a policy perspective, we are interested in exploring whether regulatory actions should be focused on the entire industry or on just a small segment of vulnerable funds.

Insights into the nature of the fund flows during the crisis can be gained by examining the distribution of flows on each day, that is, the average percentage outflows in the $10^{\text {th }}, 50^{\text {th }}$ (median), and $90^{\text {th }}$ quantiles (ranked by outflows) of funds. Figure 3 shows such quantile estimates for prime institutional funds (top panel) and for prime retail funds (bottom panel).

Note that the distribution of percentage flows is fairly tight, as indicated by the vertical distance between the $10^{\text {th }}$ and $90^{\text {th }}$ quantiles, during the period ending one week prior to the Lehman bankruptcy announcement (i.e., up to Friday, September 5, 2008). Then, the distribution widens, as shown by the days prior to the Lehman bankruptcy (i.e., from September 8-12). Finally, the distribution further substantially widens on September 15, and the following couple of days, before again tightening and becoming more stable. This finding indicates that investors viewed funds as being very heterogeneous. While the median prime institutional fund experienced only mild outflows during the crisis, funds in the left tail (of the outflow distribution) experienced extremely large outflows. For instance, the outflow on September 17 approached $20 \%$ of total net assets in 
the $10^{\text {th }}$ quantile - in other words, the $10 \%$ worst affected funds experienced outflows of $20 \%$ or higher of prior-day total net assets on a single day! However, on that same day, the median fund quantile experienced average outflows of only about $2 \%$. Finally, while the distance between $10^{\text {th }}$ and $90^{\text {th }}$ quantiles decreases substantially, it remain wider than its value during early September for several weeks following the week of September 15-19.

The lower panel of Figure 3 shows results for prime retail funds. While the pattern of the distribution is qualitatively similar to that of prime institutional funds, the distribution remains much tighter (note that the graph has been magnified, so that the difference between the $10^{\text {th }}$ and $90^{\text {th }}$ quantiles are, at most, roughly $5 \%$ of total net assets on September 18.) This result indicates, as we have shown earlier in this paper, that retail investors did not respond to the crisis in a significant way, although there is evidence of a "mild-run" in the left tail of the distribution.

In conclusion, Figure 3 shows considerable heterogeneity in the behavior of prime institutional fund (net) flows around the time of the crisis. Whereas the median fund hardly experienced any outflows, even at the peak of the crisis on September 17, the bottom $10 \%$ of funds saw outflows in excess of $20 \%$ on a single day, followed by outflows around $10 \%$ on the day after and more than $5 \%$ on the third day of the crisis. In sharp contrast, more than $10 \%$ of the funds experienced inflows on all days during the crisis, which may have originated from funds experiencing outflows. A similar, but more muted pattern is seen in prime retail fund flows. For these funds, the median fund experienced very small net flows during the crisis, whereas the top $10 \%$ of funds experienced steady inflows of about one percent per day on most days.

\subsubsection{Persistence in Flows}

So far we have documented the size of total outflows, as well as cross-sectional differences in outflows. In this section, we study flow dynamics, which can help to shed light on possible liquidity spirals, see, e.g., Brunnermeier and Pedersen (2008). For example, if persistence in outflows is especially high among funds with the highest prior-day outflows, then this suggests that prior withdrawals can create an amplification effect and potentially lead to runs on individual funds in the absence of a mechanism for stopping the run. 
To summarize whether the average persistence of fund flows changed around the time of the crisis, we first provide estimates based on panel regressions of the form

$$
y_{i t}=\alpha_{t}+\phi y_{i t-1}+\varepsilon_{i t}
$$

where $y_{i t}=\left(T N A_{i t}-T N A_{i t-1}\right) / T N A_{i t-1}$ is the estimated flow rate for fund $i$ on day $t$. The persistence measure, $\phi$, is obtained using a five-day rolling estimation window.

Figure 4 presents the $\mathrm{AR}(1)$ coefficient from this regression for prime institutional funds (top row of graphs) and prime retail funds (bottom row). Prior to the crisis, the average daily autocorrelation in prime institutional flows hovers near zero. During the crisis, the autocorrelation spikes to almost 0.6 , followed by another spike that exceeds 0.4 at the end of September, before subsuming again. This illustrates that fund flow persistence increases dramatically during and after the crisis, consistent with run behavior by investors.

The plots for the prime retail funds show that the average autocorrelation in these funds' flows went from negative values prior to the crisis to a slightly positive value, only to decline to the negative range before experiencing a local peak again (albeit at a negative value) in early October. It is important to note that negative autocorrelation can occur for many reasons unrelated to any type of strategic behavior by investors. For example, it is not unusual for investors to sell stocks or bonds, which results in money being credited to a money fund, then to transfer the money to a checking account or to purchase other stocks or bonds. However, since settlement occurs with some delay, the money fund account experiences negatively correlated flows due to these normal portfolio rebalancing activities.

As a different perspective to the persistence in outflows, Figure 5 shows differences in flows for terciles of funds formed on lagged flows. Each day, we sort all prime institutional funds into three groups with equal numbers of funds, based on the previous day's fraction flows. Among the tercile of funds with the greatest outflows on the previous day (Tercile 1), both the median (-10\%) and bottom $10 \%$ of funds (-20\%) suffered substantial outflows. By comparison, median outflows among the two-thirds of funds that had the smallest prior-day outflows (Terciles 2 and 3) were not very large. Retail flows exhibit a similar pattern. 
A nonparametric measure of persistence in fund flows is provided by a transition matrix that shows how individual funds transition across groups sorted by prior-day fraction flows. For the terciles described above, we compute the aggregate flows for each fund within each tercile over the following five trading days. Finally, we rank funds into new terciles based on this five-day percentage flow, then compute the proportion of funds, from each first-day tercile, that end up in each following five-day tercile. This process is repeated each day, and the daily transition probabilities are plotted in Figure 6.

The three panels on the left side of the figure show results for each daily tercile of prime institutional funds, ranked on percentage outflows. For instance, the top plot on the left side shows that about 35\% of funds in the bottom flow tercile, T1 (those with the biggest outflows), on September 1 end up in the bottom flow tercile over the following five days, close to the $33 \%$ that we would expect if there were no persistence in outflows. This Tercile 1 graph shows that transitions occur roughly randomly (close to 33\%) up to about one week prior to the Lehman bankruptcy. Afterwards, funds tended to stay within $\mathrm{T} 1$ (with over $60 \%$ probability) for a few days, then the transition probabilities subsided almost back to the value expected under random transitions (33\%). Note that patterns in Terciles 2 and 3 (the middle and bottom graphs) are consistent with Tercile 1 driving most of the transitions. That is, funds in Terciles 2 and 3 tend to remain in one of these two terciles, but tend to not move to Tercile 1.

The time-series patterns in transition probabilities indicate that the majority of persistence in flows during the peak weeks of the crisis occur among the highest prior-day outflow funds. High outflow funds during one day tend to remain high outflow funds during the following days. This evidence is, again, consistent with our prior findings of this paper - that investor runs during the money fund crisis were limited to a small segment of funds.

Similar transition probability plots are shown on the right side of the figure for prime retail funds. Interestingly, although persistence in outflows does not appear to be as dramatic as it is for prime institutional funds during the week following the Lehman bankruptcy, the persistence of funds in Tercile 1 remains higher than expected (under random transitions) for a much longer period. This finding indicates that retail investors continued to move their money out of funds 
that had experienced initial outflows, even after the Treasury and Federal Reserve had announced insurance and support programs. Perhaps retail fund investors exhibited a delayed reaction to the money fund crisis, as well as to the rescue programs of the Treasury and Fed.

To summarize, Figure 6 shows that prime institutional funds that experience large initial outflows during the crisis continue to see massive outflows over the next five days. Similarly, funds in the top (third) tercile, i.e., funds that experience large initial inflows (or smaller outflows) during the crisis continue to see further inflows during the following days. The findings suggest considerable persistence in the funds' flows during the period: those funds that initially experienced a large outflow were highly likely to see a continuation of being among the funds with the greatest subsequent outflows during the ensuing five-day period. This also suggests separation of funds into "types" and only scant evidence of mean reversion in (relative) fund flows during and after the crisis period.

The persistence in outflows during the crisis could be due to some funds having "fundamentals" that were viewed by investors as being more risky than other funds. Or, it could also be due to investors exhibiting an amplified aversion to funds with certain fundamentals. Finally, it can also be due to investors basing their redemption decisions purely based on prior-day flow information, independent of fundamentals. Our next sections explore which of these alternative explanations appear to drive the extreme outflows experienced by some funds during the crisis.

\subsubsection{Effect of Covariates}

We next determine whether funds with different characteristics experience different outflows during the crisis. To accomplish this, we study the effect of five characteristics:

- Average yield, AVGYIELD, defined as the portfolio weighted-average promised yield of security holdings,

- Expense ratio, EXPR,

- Standard deviation of daily fund flows, FLOWSTDEV, 
- Proportion of money market mutual fund assets represented by institutional shareclasses at the complex level, PIPERC, and

- Fund size, LOGTNA (the sum of total net assets of all shareclasses of a given money market fund).

Figure 7 presents univariate plots of the daily quantiles for prime institutional fund flows for the bottom (the five left panels) and top (the five right panels) terciles formed on fund characteristics. The plots show that funds with the largest yields (top tercile, shown in the graph on the top right) exhibit the greatest outflows, with outflows being particularly strong among the bottom decile of these high yield money funds. Funds with higher yields are likely to hold riskier portfolios that are harder to liquidate, and, so, could be more exposed to runs. This pattern is strong evidence that prime institutional investors understood the risks of different funds, and focused their "run behavior" on those funds most exposed.

We see a much bigger effect of expense ratio on fund flows among funds in the lowest tercile of the expense ratio distribution, implying that funds with the highest expense ratio saw much smaller outflows than funds with small expense ratios (which are predominantly more-sophisticated institutional investors). Funds in the top third of flow volatility are more likely to experience either very large outflows or large inflows, compared with funds in the bottom tercile. This pattern indicates a that certain funds are exposed to a "hot money" effect; that is, sophisticated institutions appear to focus their investments on certain funds. A large percentage of institutional money, measured at the fund complex level, also seems to increase the magnitude of outflows, indicating that investors considered whether the complex could withstand a run by its institutional investors (i.e., whether the complex could credibly backstop the funds). Finally, there is a very clear effect of fund size, with the largest funds clearly being more strongly exposed to outflows than the smallest funds.

Figure 8 shows a set of similar non-parametric plots for prime retail funds. Again, we see that funds at the bottom tercile of the expense ratio distribution experience larger outflows than funds at the higher end of the expense ratio distribution. Similarly, funds with the highest prior-measured volatility of flows have greater outflows and inflows than funds with lower flow volatility. Finally, 
outflows are much less related to fund size among retail funds, relative to our prior finding of large percentage outflows among the largest institional funds.

\section{Methodology}

The empirical results presented so far provide conclusive evidence that it is important to adopt an estimation methodology that captures heterogeneity in the cross-sectional distribution of fund flows in order to properly infer the drivers of run-like behavior in some money funds during the crisis. In this section we discuss how we accomplish this.

Theories of bank runs differ in terms of how large a role they attribute to fundamentals versus simple common shocks, so we focus on directly modeling cross-sectional differences. As a simple way to capture differences between (common) shocks to all funds versus shocks specific to funds in the left versus right tail of the cross-sectional distribution, we focus on modeling three conditional quantiles, namely the 10th, 50th (median) and 90th quantiles. Moreover, to facilitate interpretation of the results, we anchor the model on the effect of common shocks that affect the location (median) of the return distribution. We then add (or subtract) pieces that quantify the difference between the effect of covariates on funds in the left or right tails of the cross-sectional distribution of fund flows. In this way, we can determine whether fundamentals, and non-fundamentals, differentially affect funds. For example, perhaps investors put a heavy weight on the riskiness of a fund's holdings during the early stages of a crisis, but place less weight during later stages-after risky funds have exhibited substantial outflows.

Our econometric approach emphasizes time-varying dynamics in fund flows as well as crosssectional heterogeneities in fund flows. These two features turn out to be an important part of our data and, so, must be accommodated in the empirical analysis. Conventional approaches such as (panel) OLS fail to fully account for these effects, so we adopt an alternative methodology. Following the study by Koenker and Bassett (1978), a variety of methods have been developed for estimating conditional quantiles. Given a dependent variable, $Y_{i, t}$, and a set of conditioning variables, $X_{i, t}$, we can write

$$
Y_{i, t}=f\left(X_{i, t}, \beta\right)+\epsilon_{i, t},
$$


replacing the usual regression restriction that $E\left[\epsilon_{i, t} \mid X_{i, t}\right]=0$ with the restriction that $P\left[\epsilon_{i, t}<\right.$ $\left.0 \mid X_{i, t}\right]=\alpha$, for some $\alpha \in(0,1)$. As we change $\alpha$, we change the probability index associated with the quantile of interest. If $\alpha=0.5$, this is a model for the conditional median, and the key identifying assumption is that the median of $\epsilon_{i, t}$ conditional on $X_{i, t}$ is zero. If $\alpha=0.1,(2)$ is a model for the 10th percentile conditional on $X_{i, t}$.

To incorporate multiple quantiles in a way that focuses on the differences ("quantile spacings") between the median fund versus left and right tail funds, we adopt the following specification:

$$
\begin{array}{ll}
Y_{i, t}=f_{0}\left(X_{i, t}, \beta\right)=X_{i, t}^{\prime} \beta_{0}+\epsilon_{i, t}^{0} & P\left[\epsilon_{i, t}^{0}<0 \mid X_{i, t}\right]=0.5 \\
Y_{i, t}=f_{1}\left(X_{i, t}, \beta\right)=X_{i, t}^{\prime} \beta_{0}-\exp \left[X_{i, t}^{\prime} \beta_{1}\right]+\epsilon_{i, t}^{1} & P\left[\epsilon_{i, t}^{1}<0 \mid X_{i, t}\right]=0.1 \\
Y_{i, t}=f_{2}\left(X_{i, t}, \beta\right)=X_{i, t}^{\prime} \beta_{0}+\exp \left[X_{i, t}^{\prime} \beta_{2}\right]+\epsilon_{i, t}^{2} & P\left[\epsilon_{i, t}^{2}<0 \mid X_{i, t}\right]=0.9 .
\end{array}
$$

Note that, in this specification, $\beta_{0}$ captures the common effect of $X$-variables that affect all funds; $\beta_{1}$ captures the additional effect of shocks that only affect the left tail of the distribution-in our case, those funds most strongly affected by outflows; finally, $\beta_{2}$ captures the additional effect of shocks that only affect the right tail of the distribution, i.e., those funds with the smallest outflows/largest inflows. We follow the convention in the literature by assuming that the median can be modeled as a linear function of $X_{i, t}$, but treat the other quantiles in a different manner. Specifically, since the exponential function is always non-negative, our specification ensures that $\beta_{1}$ captures the effect of covariates in the left tail, while $\beta_{2}$ captures the effect of covariates in the right tail and also guarantees that the conditional quantiles never cross.

An alternative way to write the data generating process for $Y_{i, t}$ is

$$
Y_{i, t}=X_{i, t}^{\prime} \beta_{0}-D_{i, t} \exp \left[X_{i, t}^{\prime} \beta_{1}\right] \eta_{i, t}+\left(1-D_{i, t}\right) \exp \left[X_{i, t}^{\prime} \beta_{2}\right] \eta_{i, t}
$$

where $\eta_{i, t}$ is a nonnegative random variable with $P\left[\eta_{i, t}<1 \mid X_{i, t}\right]=0.8$ and $D_{i, t}$ is a Bernoulli random variable which equals 1 with probability $0.5 .{ }^{18}$ If $\beta_{1}=\beta_{2}$, this is consistent with a simple mean-variance model where the variance is a loglinear function of $X_{i, t}$. When $\beta_{1} \neq \beta_{2}$, these

\footnotetext{
${ }^{18}$ To see this, note that if $P\left(\eta_{i, t}<1 \mid X_{i, t}\right)=0.8, P\left(Y_{i, t}<X_{i, t}^{\prime} \beta_{0}-\exp \left[X_{i, t}^{\prime} \beta_{1}\right] \mid X_{i, t}\right)=P\left(D_{i, t}=1 \mid X_{i, t}\right) \times P\left(\eta_{i, t}>\right.$ $\left.1 \mid X_{i, t}\right)=0.5 \times(1-0.8)=0.1$.
} 
are analogous to "semi-variances" instead, where $\beta_{1}$ and $\beta_{2}$ governs the variance of bad and good shocks, respectively. The latter way of writing the DGP also mirrors the manner in which we estimate the relevant parameters.

Following the method in Schmidt (2012), we sequentially estimate the parameters of interest using a series of standard linear quantile regressions. Specifically, we first estimate $\beta_{0}$ using standard linear quantile regression. Next, we estimate $\beta_{1}$ and $\beta_{2}$ by splitting the sample into two halves based on the signs of the residuals and performing an additional linear quantile regression on the log of these residuals. Using the positive residuals, we can estimate $\beta_{2}$. To see why this works, note that if $Y_{i, t}-X_{i, t}^{\prime} \beta_{0}>0, Y_{i, t}-X_{i, t} \beta_{0}=\exp \left[X_{i, t}^{\prime} \beta_{2}\right] \eta_{i, t}$. Taking logs, we get that $\log \left[Y_{i, t}-X_{i, t}^{\prime} \beta_{0}\right]=$ $X_{i, t}^{\prime} \beta_{2}+\log \eta_{i, t}$. Given our assumption that $P\left[\eta_{i, t}<1 \mid X_{i, t}\right]=P\left[\log \eta_{i, t}<0 \mid X_{i, t}\right]=0.8$, the transformed model satisfies the standard assumptions for linear quantile regression with $\alpha=0.8$. To get feasible estimators, $\beta_{0}$ is replaced with $\hat{\beta}_{0}$, the initial estimate from the quantile regression for the median. An analogous procedure works for the negative residuals, enabling us to estimate $\beta_{1}$. We calculate standard errors using simple bootstrap procedures. ${ }^{19}$

Our model for conditional quantiles has an additional interpretation which is particularly useful in a panel context. Imagine that

$$
Y_{i, t}=X_{i, t}^{\prime} \beta_{0}+\xi_{0, t}-D_{i, t} \exp \left[X_{i, t}^{\prime} \beta_{1}+\xi_{1, t}\right] \eta_{i, t}+\left(1-D_{i, t}\right) \exp \left[X_{i, t}^{\prime} \beta_{2}+\xi_{2, t}\right] \eta_{i, t}
$$

where $\left(\xi_{0, t}, \xi_{1, t}, \xi_{2, t}\right)^{\prime}$ is a vector of unobserved, time-specific shocks. $\xi_{0, t}$ is a shock which hits all funds, regardless of whether they receive a good or a bad shock. $\xi_{1, t}$ scales up or down the variance of the bad shock, while $\xi_{2, t}$ scales up or down the variance of the good shock. Hence, $\beta_{1}$ and $\beta_{2}$ have useful factor-loading interpretations: If $X_{i, t}^{\prime} \beta_{1}=0$, the variance of the fund's bad shock is the aggregate shock; If $X_{i, t}^{\prime} \beta_{1}>0$, the sensitivity to the aggregate shock increases. This specification makes sense in our application given that certain fund-specific exposures only matter on days where investors are concerned about them. Again, implementation is straightforward, since these effects

\footnotetext{
${ }^{19}$ Bootstrap procedures, when applicable, are generally thought to be more reliable than asymptotic approximations in quantile regression applications. We use the paired bootstrap for the cross-sectional event study analysis and a clustered bootstrap for the panel analysis. For the latter, we cluster at the fund level, which corrects for arbitrary serial correlation in the residuals within funds.
} 
can be included by augmenting the $X_{i, t}$ vector with time dummy variables.

\section{Estimation Results}

This section presents more formal estimation results. We start off with conventional OLS panel estimation results and then show how these change when we consider our more flexible quantile regression model.

\subsection{OLS Panel Estimates}

So far, we have focused our analysis on differences in the flows experienced by individual funds as well as differences in the dynamics of outflow, i.e., the degree of persistence, observed across funds. In this section, we more formally estimate models that attempt to identify the characteristics of a fund that may make it more susceptible to run-like behavior by investors.

As a first cut, and for later comparison, Table 5 presents OLS panel estimates of fund-level flows as a function of the covariates described in a prior section, in addition to lagged fund flows, measured relative to the lagged average fund flows (computed as a cross-sectional average), $y_{i t-1}-\bar{y}_{t-1}$, and divided into above-average lagged flows, $y_{i t-1}-\bar{y}_{t-1}>0$, and below-average lagged flows, $y_{i t-1}-\bar{y}_{t-1}<0$. By separately considering the effect of flows above and below the cross-sectional average, we can see if persistence of fund flows differs among funds with the (relatively) largest inflows or outflows.

Our specification is, thus,

$$
\begin{aligned}
y_{i t}= & \alpha_{t}+\beta_{1} \max \left(y_{i t-1}-\bar{y}_{t-1}, 0\right)+\beta_{2} \min \left(y_{i t-1}-\bar{y}_{t-1}, 0\right)+\beta_{3} A V G Y I E L D_{i t}+ \\
& \beta_{4} E X P R_{i t}+\beta_{5} F L O W S T D E V_{i t}+\beta_{6} P I P E R C_{t}+\beta_{7} L O G T N A_{i t}+\varepsilon_{i t} .
\end{aligned}
$$

We present results separately for the pre-crisis period (September 10-16, 2008), the crisis period (September 17-19), and the "post-crisis" period (September 22-October 17). ${ }^{20}$ The run on the

\footnotetext{
${ }^{20}$ Although Lehman declared bankruptcy on September 15, the first major impact of the crisis on money funds was on September 17. The "post crisis" period is not one that we consider to be free from crisis effects, but it is distinct from the crisis week because of the announced federal guarantee programs.
} 
money market funds greatly intensified between September 17 up to September 19, the date where the Federal Reserve announced its backstop for mutual funds. The pre-crisis period coincides with the beginning of leakage of money from the funds leading up to the Lehmann crisis. The post-crisis period ends on October 17. This analysis allows us to address whether fund flow dynamics were altered in interesting ways during the crisis.

As shown in Table 5, the AR(1) coefficient indicates that persistence in institutional fund flows (both inflows and outflows) was quite strong during the pre-crisis period-a persistence coefficient of 0.3169 is observed. This finding is evidence of institutions selectively piling into certain funds, perhaps as they left money funds that were not registered 1940-Act funds in a flight to safety. In addition, institutions selectively piled out of other funds. The $\operatorname{AR}(1)$ coefficient is much weaker during the crisis period for outflows, which is presumably evidence that there was not a simple amplification effect operating during the crisis (we will revisit this finding in our next section). During the post-crisis period, outflows exhibit some amplification effects.

Next, consider the effect of fund characteristics on flows. Most of the fund characteristics exhibit significant coefficients during the crisis. During this period, funds with higher weighted-average portfolio yields experience greater outflows, as shown by our graphical results of Figure 8. Again, this is likely a result of investor concerns that funds with higher yields are riskier and, thus, more prone to runs than funds with a lower yield. In contrast, funds with higher expense ratios experience smaller outflows during and after the crisis, likely due to a clientele effect; investors in funds with higher expense ratios are likely to be less sophisticated and perhaps in less need of liquidity than investors in funds with lower expense ratio. Funds belonging to complexes with a higher percentage of institutional (money fund) investors also experience higher outflows, and the largest funds are most exposed to outflows. Flow volatility does not significantly affect flows, although this variable is highly correlated with the yield variable.

Specifications that do not include lags of the dependent variable (flows) exhibit coefficients for exogenous variables that are similar to those that include lags. Thus, investors react to lagged flows in addition to their reaction to fundamentals.

To summarize, fund characteristics ("fundamentals") clearly matter for institutional fund flows, 
particularly during the crisis period. Very different results emerge for the prime retail funds. In sharp contrast with the prime institutional funds, there is negative persistence in the flows to the prime retail funds, which is likely due to the normal movement of money into and out of money funds as a temporary holding while transitioning a portfolio or liquidating all or part of a portfolio of stocks or bonds. Moreover, no characteristic seems to matter greatly for prime retail funds other than fund size which again affects flows negatively so that larger funds experienced the greatest outflows, particularly during the crisis.

\subsection{Quantile Regressions}

The OLS regression results in Table 5 ignore any heterogeneity across funds in investor persistence in outflows, or the impact of fund characteristics on investor outflows. However, our earlier results in Figures 5-8 show that such heterogeneity is, in fact, important. These non-parametric plots show that outflows are especially persistent among a minority of funds having certain characteristics. This evidence suggests that we should adopt a regression approach that allows for differences in the effect of covariates across the distribution of funds.

To this end, Table 6 presents fund-level panel quantile regressions. Column 1 shows coefficient estimates, and p-values (beneath the point estimates), for the model over the February 1 to September 9, 2008. This period is used as a "normal period," against which to compare the pre-crisis (September 10-16), crisis (September 17-19), and "post-crisis" (September 22-October 17) periods.

First consider the effect of a common shock which, according to our model (4), affects the entire distribution of fund flows. The persistence in the effect of a common shock is more than double that of funds experiencing above-average outflows $\left(y_{i t-1}-\bar{y}_{t-1}<0\right)$ than for funds with above-average inflows $\left(y_{i t-1}-\bar{y}_{t-1}>0\right)$, particularly during the crisis (a first-order autocorrelation of 0.57 versus 0.23$)$, but also during the pre-crisis period (0.24 versus 0.12$)$. In contrast, there is very little persistence in the effect of prior-day flows on a common shock during the post-crisis.

Turning to the coefficients on fund and investor characteristics, Table 6 shows that higher yields are associated with larger outflows during the crisis. However, this impact is small for the common 
shock (entire distribution) effect: a one standard deviation increase in yield is associated with a 64 basis point increase in log daily outflows during the crisis days. Yields also only marginally affect flows during the pre- and post-crisis periods. Two other fund characteristics are also associated with higher outflows, predominantly during the crisis: (1) funds with lower expense ratios and (2) funds that are larger in total net assets under management. Note that higher lagged flow standard deviation is also associated with crisis-period outflows, although the coefficient is only marginally significant (with a p-value of $11.7 \%$ ). In general, the results for the common shock component are consistent with those from the panel OLS estimation of Table 5.

Further insights can be gained from examining the effects of covariates on the left- and righttails, which are shown in the middle and bottom panels, respectively. First, note that the lagged standard deviation of daily flows, FlowSTDEV, exhibits a large effect (which is also statistically significant) on funds in both tails of the daily flow distribution. A higher flow standard deviation has a greater negative impact on flows in the left tail, and a greater positive impact on flows in the right tail, during all periods. ${ }^{21}$ This finding reflects that high lagged flow standard deviation persists, and that these funds are more likely to end up in the tails of the flow distribution (a "hot money" effect on certain funds).

In contrast, the coefficients on expense ratio, $E X P R$, are negative in the tails, meaning that lower expense ratio funds indeed exhibit more dramatic outflows (left tail) or inflows (right tail)again, a tendency for hot money to prefer these types of funds. Interestingly, the level of institutional money managed (in money market mutual funds) at the complex level has an asymmetric effect on the tails. Funds that are a part of complexes with higher levels of institutional money have greater left tail exposure (i.e., large outflows) during the crisis, whereas this variable has little effect on the right tail. This finding indicates that money did not generally flow from high institutional money complexes to low institutional money complexes. This finding is also consistent with Figure 1, which indicates that outflows from prime institutional funds (especially those that were part of complexes with a large proportion of institutional funds) flowed to government institutional money market funds. Higher average yields, $A V G Y I E L D$, have a (negative) impact on funds in

\footnotetext{
${ }^{21}$ Note that the positive coefficient of 0.35 during the crisis days in the left tail corresponds to a negative relation between lagged flow standard deviation and current day flows, as specified in Equation (3), while a positive coefficient of 0.45 corresponds to a positive relation in the right tail.
} 
the left tail, as shown by the left-tail coefficient of 0.23 . A one standard deviation increase in yield is increases the fund's exposure to a bad shock by $23 \%$.

Yield has an increased impact on the right tail, too, with a coefficient of 0.11 . Finally, there is evidence that fund size has a greater impact on flows in the flow tails during the crisis days, but less impact during the post-crisis days.

Table 7 repeats the analysis for prime retail funds. There is no significant evidence of persistence in the effect of common shocks on retail fund flows before or after the crisis, while above-average flows are mildly persistent during the crisis. Higher yields are associated with bigger outflows during the crisis, but do not differentially affect the tails (unlike our results noted above for institutional shareclasses). Also, funds with higher expense ratios see smaller outflows before and after the crisis, although this variable had no effect during the crisis, indicating that some retail investors may have been more sophisticated than others. Once again, larger funds experience greater outflows.

Flow volatility has a much higher impact on the left and right tails of the retail flow distribution, both before and after the crisis, though not during the crisis. Interestingly, right-tail (inflows) exhibit substantial persistence prior to the crisis with a coefficient of 0.30 , but do not exhibit significant persistence during the crisis days.

Figure 9 presents plots of the common shocks from the panel OLS vs. quantile regressions for both institutional and retail funds. For the common shocks to the distributions $\left(\xi_{0, t}\right.$ in Equation (5), and shown in the graphs on the left of the figure), there are large similarities between the OLS and quantile regressions, such as the large outflow shocks that affect all prime institutional funds during September 17-19. However, the additional shocks to the tails ( $\xi_{1, t}$ and $\xi_{2, t}$ in Equation (5), and shown in the graphs on the right of the figure), estimated by the quantile regressions, show that these shocks to the tails (which are ignored by the OLS analysis) are as important as (i.e., of the same magnitude) or larger than the common shocks to the distribution of flows. That is, the quantile regressions expose the very uneven level of flow shocks that occur across the distribution-shocks have a much larger impact on the tails, especially the left tail.

Figure 10 provides a different view of the effect that flows have at the peak of the crisis on September 17, 2008. The graphs plot the effect of changing the average gross yield in a range 
between $2.4 \%$ and $3.4 \%$ on log flows, and can be viewed as an elasticity of flows with respect to changes in portfolio yields. We can clearly see that the effect of increasing portfolio yield from its mean by one standard deviation is very minor for funds in the right tail of the distribution, i.e., funds with the largest inflows (smallest outflows). A somewhat bigger effect (but still relatively mild) of raising the yield by one standard deviation is seen on the median fund, which experiences a greater outflow as a result of the higher yield. By far the largest effect is seen in the left tail of the flow distribution, which shifts markedly to the left in the flow distribution as a result of an increase in yield.

To summarize our results of this section, we find strong evidence of persistence in flows (especially outflows) in prime institutional funds during the crisis period as well as a significant negative impact of portfolio average yield on flows. Persistence in flows (first-order autocorrelation) impact the entire distribution similarly (i.e., tail effects are not significantly different), while higher yield pushes funds in the left tail of the flow distribution to even more extreme levels of outflows. Flow volatility also has a significantly different impact on the tails of the flow distribution, with higher flow volatility pushing funds further into the tails. Expense ratio also has a more muted effect, but still affects the tails differentially from the median of the distribution. Finally, fund size affects mainly the tails, and does so in an asymmetric way (the right tail is more impacted by fund size). For prime retail funds, we find almost no significant predictors of flows during the crisis days, but some post-crisis persistence in the left tail (consistent with retail investors reacting slowly to the news of the money market fund crisis that developed in institutional funds).

\subsection{Dynamics in Flows Following a Shock}

Figure 11 graphs forecasts of fraction flows, for the tails and for the median fund, as provided by our fitted quantile model of the prior section for institutional funds. Here, we illustrate the (fitted) flow dynamics following a common shock to flows of $-10 \%$ (i.e., an outflow of $10 \%$ ), measured relative to the average fund flow, or a shock to flows of $+10 \%$ (an inflow relative to the average fund). As a baseline reference, the middle graph in Figure 11 shows that only the right tail of prime institutional funds experience positive flows conditional on prior fund flows being set at their 
median value. Moreover, as shown in the left graph, when funds are hit with a $10 \%$ outflow shock, the median fund experiences far greater net outflows than we would expect if only the location of the fund flow distribution shifted, i.e., in the absence of heterogeneity in the effect of past flows on current flows.

To simulate the impact of perturbations in the value of exogenous variables on multi-period flow distributions, we note from Figure 12 that the standardized residual density from the baseline model for institutional funds is very closed to a properly parameterized Laplace distribution. We, therefore, draw shocks from this parametric distribution in the multi-period simulations.

Results from this exercise are shown in Figure 13. At the beginning of each window (September 10), we fix each of the explanatory variables at its average plus or minus one standard deviation. The results show that there are long-lasting effects of changes to many covariates, especially for funds with the greatest left tail exposure. Most notably, reducing the expense ratio or increasing the volatility by one standard deviation leads to a cumulative outflow that approaches $40 \%$ by September 26, 2008, relative to the baseline scenario, while increasing the average yield, fund size, or the percentage of institutional investor money by one standard deviation is associated with additional cumulative outflows of roughly $30 \%$. Most importantly, note the asymmetry in the impact of the covariates on flows: a one standard deviation increase, for all variables, exhibits quite different outflow impacts than a one standard deviation decrease.

\section{Robustness Analysis and Extensions}

Table 8 presents results when the asymmetry in the autoregressive effect of flows is measured around zero, versus the alternative of centering at the average flow, $\bar{y}_{t-1}=0$, that was used in Table 6 . The effect of this change, shown in Table 8, alters the autoregressive dynamics somewhat, although their relative magnitudes are similar to those in Table 6, while the coefficients for the covariates do not change much, in most cases.

Table 9 extends Table 6 to allow for cross-category dynamics in the fund-level panel quantile regressions, principally by including variables MULTCAT and LAGOTHER. MULTCAT is an indicator (dummy) variable that equals 1 only if a money market fund has both prime institutional 
and prime retail funds. This variable captures whether investors view funds with a mixed investor base differently. For example, a run imposed by institutional investors may result in retail investors holding the remaining illiquid assets-which results in a run among retail investors.

The coefficient on LAGOTHER, where the dependent variable is daily prime institutional (retail) fund flows, captures the effect of lagged prime retail (institutional) fund flows. The largest effect is seen among prime institutional funds residing in the left tail of flows during the crisis. For these funds, a large and highly significant effect of lagged retail flows of -0.2457 is estimated. The coefficient on MULTCAT does not indicate any consistent effect of mixed investors on flows of either investor class. For the simpler OLS panel regressions shown in Table 10, the effect of lagged retail flows on prime institutional flows is positive and highly significant during the crisis.

\section{Conclusion}

This paper studies money fund runs during the crisis period of September and October 2008. We find that correlated withdrawals were especially pronounced among money funds that catered predominantly to institutional investors, although we also find weak evidence of correlated withdrawals among retail money funds during the crisis. This finding indicates that "sophisticated" investors mainly present a "bank-run" risk (a negative externality) to each other, and present a weaker risk to "passive" (retail) investors in same-complex money funds.

Second, we find that runs were more pronounced among funds that had less liquidity, in terms of their lower holdings of securities that matured with seven days. We also find that money fund runs were more likely when the fund didn't have "deep pocket backing," indicating that investors infer that funds are guaranteed by their management company. And, finally, institutional investors, for the most part, moved their money into U.S. government (only) money market funds in the same fund complex, indicating that they were sophisticated enough to know when not to rely on the management company's liquidity-provision. 


\section{Bibliography}

\section{References}

[1] Alonso, I., 1996, On avoiding bank runs, Journal of Monetary Economics.

[2] Angeletos, G-M, C. Hellwig, and A. Pavan, 2007, Dynamic Global Games of Regime Change: Learning, Multiplicity, and the Timing of Attacks, Econometrica 71, 711-756.

[3] Ben Rephael, Azi, Shmuel Kandel, and Avi Wohl, 2009, Measuring Investor Sentiment with Mutual Fund Flows, Journal of Financial Economics.

[4] Brunnermeier, M.K., and L.J. Pedersen, 2008, Market Liquidity and Funding Liquidity. Review of Financial Studies 22, 2201-2238.

[5] Bryant, John, 1980, A model of reserves, bank runs, and deposit insurance, Journal of Banking and Finance.

[6] Chen, Qi, Itay Goldstein, and Wei Jiang, 2010, Payoff Complementarities and Financial Fragility: Evidence from Mutual Fund Outflows, Journal of Financial Economics 97, 239262.

[7] Cooper, R., and T.W. Ross, 1998, Bank runs: Liquidity costs and investment distortions, Journal of Monetary Economics.

[8] Covitz, D., N. Liang, and G. Suarez, 2009, The Evolution of a Financial Crisis: Panic in the Asset-Backed Commercial Paper Market, Journal of Finance, forthcoming.

[9] Diamond, Douglas W., and Philip H. Dybvig, 1983, Bank runs, deposit insurance, and liquidity, Journal of Political Economy.

[10] Goldstein, I., and A. Pauzner, 2005, Demand-deposit contracts and the probability of bank runs, Journal of Finance.

[11] Investment Company Institute, 2009, Report of the Money Market Working Group. 
[12] Jacklin, C.J., and S. Bhattacharya, 1988, Distinguishing panics and information-based bank runs: Welfare and policy implications, Journal of Political Economy.

[13] Jank, Stephan, and Michael Wedow, 2010, Sturm und Drang in Money Market Funds: When Money Market Funds Cease to Be Narrow, Working Paper.

[14] Koenker, R., and G. Bassett, 1978, Regression Quantiles. Econometrica 46 33-50.

[15] Morris, S. and H.S. Shin, 1998, Unique Equilibrium in a Model of Self-Fulfilling Currency Attacks, American Economic Review 88, 587-597.

[16] Peck, J., and K. Shell, 2003, Equilibrium bank runs, Journal of Political Economy.

[17] Postlewaite, A., and X. Vives, 1987, Bank runs as an equilibrium phenomenon, Journal of Political Economy.

[18] Rakowski, David, and Xiaoxin Wang, 2009, The Dynamics of Short-Term Mutual Fund Flows and Returns: A Time-Series and Cross-Sectional Investigation. Journal of Banking and Finance.

[19] Schmidt, L., 2012, Quantile Spacings: A Simple Solution to the Quantile Crossing Problem. Working Paper.

[20] Warther, Vincent A., 1995, Aggregate Mutual Fund Flows And Security Returns, Journal of Financial Economics. 
Table 1: Total Net Assets and Number of Shareholder Accounts (year-end)

Total net assets

(billions of dollars)

\begin{tabular}{|c|c|c|c|c|}
\hline \multirow[b]{2}{*}{ Year } & \multirow[b]{2}{*}{ Total } & \multicolumn{2}{|c|}{ Taxable } & \multirow[t]{2}{*}{ Tax-exempt } \\
\hline & & Government & Prime & \\
\hline 1990 & $\$ 498.3$ & $\$ 107.6$ & $\$ 307.1$ & $\$ 83.6$ \\
\hline 1991 & 542.4 & 138.0 & 314.6 & 89.9 \\
\hline 1992 & 546.2 & 151.3 & 300.1 & 94.8 \\
\hline 1993 & 565.3 & 148.7 & 313.2 & 103.4 \\
\hline 1994 & 611.0 & 147.1 & 353.5 & 110.4 \\
\hline 1995 & 753.0 & 179.2 & 450.8 & 123.0 \\
\hline 1996 & 901.8 & 217.9 & 544.1 & 139.8 \\
\hline 1997 & 1058.9 & 245.0 & 653.1 & 160.8 \\
\hline 1998 & 1351.7 & 302.8 & 860.4 & 188.5 \\
\hline 1999 & 1613.1 & 325.9 & 1082.8 & 204.4 \\
\hline 2000 & 1845.2 & 352.5 & 1254.7 & 238.0 \\
\hline 2001 & 2285.3 & 437.2 & 1575.7 & 272.4 \\
\hline 2002 & 2272.0 & 447.7 & 1549.5 & 274.8 \\
\hline 2003 & 2052.0 & 403.5 & 1360.1 & 288.4 \\
\hline 2004 & 1913.2 & 372.4 & 1230.4 & 310.3 \\
\hline 2005 & 2040.5 & 382.5 & 1324.0 & 334.0 \\
\hline 2006 & 2338.5 & 405.8 & 1566.2 & 366.4 \\
\hline 2007 & 3085.8 & 726.1 & 1894.6 & 465.1 \\
\hline 2008 & 3832.2 & 1450.3 & 1890.4 & 491.5 \\
\hline
\end{tabular}

Number of shareholder accounts*

(thousands)

\begin{tabular}{|c|c|c|c|}
\hline \multirow[b]{2}{*}{ Total } & \multicolumn{2}{|c|}{ Taxable } & \multirow[t]{2}{*}{$\underline{\text { Tax-exempt }}$} \\
\hline & Government & Prime & \\
\hline 22,969 & 2,273 & 19,305 & 1,391 \\
\hline 23,556 & 2,547 & 19,316 & 1,693 \\
\hline 23,647 & 2,817 & 18,954 & 1,876 \\
\hline 23,585 & 2,806 & 18,780 & 1,998 \\
\hline 25,383 & 3,049 & 20,295 & 2,039 \\
\hline 30,144 & 3,824 & 24,035 & 2,285 \\
\hline 32,200 & 4,147 & 25,760 & 2,292 \\
\hline 35,624 & 4,548 & 28,413 & 2,663 \\
\hline 38,847 & 4,384 & 32,058 & 2,405 \\
\hline 43,616 & 4,793 & 36,385 & 2,438 \\
\hline 48,138 & 4,888 & 40,592 & 2,659 \\
\hline 47,236 & 5,124 & 39,290 & 2,821 \\
\hline 45,380 & 5,092 & 37,634 & 2,655 \\
\hline 41,214 & 4,111 & 34,301 & 2,802 \\
\hline 37,636 & 3,651 & 31,143 & 2,842 \\
\hline 36,837 & 3,117 & 30,916 & 2,805 \\
\hline 37,067 & 3,292 & 30,714 & 3,061 \\
\hline 39,130 & 3,481 & 32,181 & 3,467 \\
\hline 38,112 & 4,160 & 30,339 & 3,613 \\
\hline
\end{tabular}


Table 2: Number of Funds and Number of Share Classes

(Year-end)

\begin{tabular}{|c|c|c|c|c|c|c|c|c|}
\hline \multirow[b]{3}{*}{ Year } & \multicolumn{4}{|c|}{ Number of funds } & \multicolumn{4}{|c|}{ Number of share classes } \\
\hline & \multirow[b]{2}{*}{ Total } & \multicolumn{2}{|c|}{ Taxable } & \multirow[t]{2}{*}{$\begin{array}{c}\text { Tax- } \\
\text { exempt }\end{array}$} & \multirow[b]{2}{*}{ Total } & \multicolumn{2}{|c|}{ Taxable } & \multirow[t]{2}{*}{$\begin{array}{c}\text { Tax- } \\
\text { exempt }\end{array}$} \\
\hline & & Government & Prime & & & Government & Prime & \\
\hline 1990 & 741 & 174 & 332 & 235 & 762 & 180 & 343 & 239 \\
\hline 1991 & 820 & 211 & 342 & 267 & 871 & 228 & 364 & 279 \\
\hline 1992 & 864 & 234 & 351 & 279 & 914 & 247 & 369 & 298 \\
\hline 1993 & 920 & 260 & 368 & 292 & 1,009 & 280 & 393 & 336 \\
\hline 1994 & 963 & 271 & 375 & 317 & 1,261 & 360 & 493 & 408 \\
\hline 1995 & 997 & 279 & 395 & 323 & 1,380 & 394 & 555 & 431 \\
\hline 1996 & 988 & 271 & 395 & 322 & 1,453 & 404 & 596 & 453 \\
\hline 1997 & 1,013 & 271 & 411 & 331 & 1,549 & 428 & 642 & 479 \\
\hline 1998 & 1,026 & 275 & 410 & 341 & 1,627 & 459 & 674 & 494 \\
\hline 1999 & 1,045 & 284 & 418 & 343 & 1,730 & 493 & 733 & 504 \\
\hline 2000 & 1,039 & 277 & 426 & 336 & 1,855 & 531 & 793 & 531 \\
\hline 2001 & 1,015 & 273 & 416 & 326 & 1,948 & 575 & 822 & 551 \\
\hline 2002 & 989 & 265 & 414 & 310 & 2,006 & 588 & 876 & 542 \\
\hline 2003 & 974 & 258 & 404 & 312 & 2,031 & 584 & 879 & 568 \\
\hline 2004 & 943 & 247 & 392 & 304 & 2,046 & 589 & 882 & 575 \\
\hline 2005 & 871 & 220 & 375 & 276 & 2,031 & 565 & 900 & 566 \\
\hline 2006 & 847 & 212 & 362 & 273 & 2,012 & 567 & 888 & 557 \\
\hline 2007 & 805 & 197 & 349 & 259 & 2,018 & 553 & 897 & 568 \\
\hline 2008 & 784 & 195 & 341 & 248 & 1,989 & 568 & 880 & 541 \\
\hline
\end{tabular}

*Number of shareholder accounts includes a mix of individual and omnibus accounts.

Note: Data for funds that invest primarily in other mutual funds were excluded from the series. Components may not add to the total because of rounding. Source: ICI Factbook, 2009 
Table 3: Net New Cash Flow ${ }^{1}$ and Components of Net New Cash Flow of Money Market Funds (\$Billions/year)

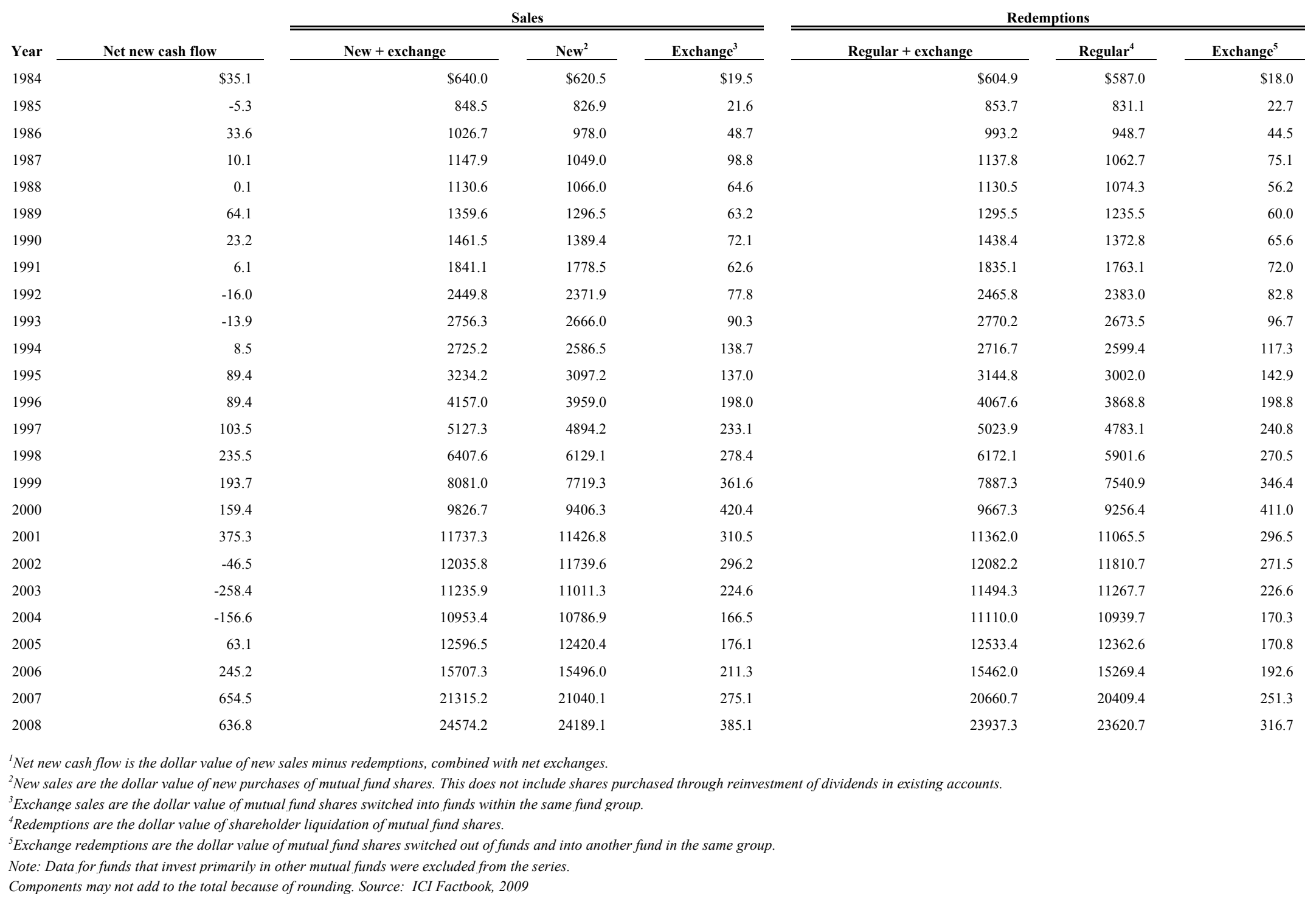


Table 4: Asset Composition of Taxable Non-Government Money Market Funds as a Percent of Total Net Assets (Year-End)

\begin{tabular}{|c|c|c|c|c|c|c|c|c|c|c|c|c|}
\hline Year & $\begin{array}{c}\text { Total net } \\
\text { assets } \\
\text { (billions } \\
\text { of } \\
\text { dollars) } \\
\end{array}$ & $\begin{array}{c}\text { U.S. } \\
\text { Treasury } \\
\text { bills \% } \\
\end{array}$ & $\begin{array}{c}\text { Other } \\
\text { Treasury } \\
\text { securities } \\
\% \\
\end{array}$ & $\begin{array}{c}\text { U.S. } \\
\text { government } \\
\text { agency } \\
\text { issues \% } \\
\end{array}$ & $\begin{array}{c}\text { Repurchase } \\
\text { agreements } \\
\% \\
\end{array}$ & $\begin{array}{c}\text { Certificates } \\
\text { of deposit } \\
\% \\
\end{array}$ & $\begin{array}{c}\text { Eurodollar } \\
\text { CDs \% } \\
\end{array}$ & $\begin{array}{c}\text { Commercial } \\
\text { paper \% }\end{array}$ & $\begin{array}{c}\text { Bank } \\
\text { notes } 1 \% \\
\end{array}$ & $\begin{array}{c}\text { Corporate } \\
\text { notes }^{2} \%\end{array}$ & $\begin{array}{c}\text { Other } \\
\text { assets }^{3} \\
\% \\
\end{array}$ & $\begin{array}{c}\text { Average } \\
\text { maturity } \\
(\text { days }) \\
\end{array}$ \\
\hline 1990 & $\$ 307.1$ & 4.3 & 2.3 & 4.7 & 3.3 & 6.8 & 8.8 & 65.0 & - & - & 4.7 & 48 \\
\hline 1991 & 314.6 & 5.8 & 3 & 4.3 & 4.1 & 10.5 & 6.9 & 59.7 & - & - & 5.8 & 56 \\
\hline 1992 & 300.1 & 2.8 & 2.6 & 7.5 & 5.1 & 10.3 & 6.7 & 57.4 & - & - & 7.4 & 59 \\
\hline 1993 & 313.2 & 2.7 & 2.5 & 11.9 & 6.4 & 7.9 & 3.2 & 52.2 & - & - & 13.2 & 58 \\
\hline 1994 & 353.5 & 2.6 & 1.3 & 11.3 & 6 & 6.3 & 4.5 & 53.2 & 2.4 & - & 12.4 & 38 \\
\hline 1995 & 450.8 & 1.5 & 1 & 9.2 & 6.5 & 8.8 & 4.4 & 52.2 & 3.7 & - & 12.6 & 60 \\
\hline 1996 & 544.1 & 0.7 & 1.9 & 8.9 & 5.4 & 12.7 & 4.3 & 50.5 & 2.3 & - & 13.3 & 56 \\
\hline 1997 & 653.1 & 0.5 & 0.8 & 5.5 & 5.6 & 14.6 & 3.7 & 51.5 & 3.2 & - & 14.8 & 57 \\
\hline 1998 & 860.4 & 0.6 & 0.9 & 9.5 & 4.9 & 12.9 & 3.6 & 48.3 & 3.9 & 5.8 & 9.6 & 58 \\
\hline 1999 & 1082.8 & 0.5 & 0.3 & 6.7 & 5.1 & 12.7 & 3.9 & 48.9 & 3.1 & 8.3 & 10.4 & 49 \\
\hline 2000 & 1254.7 & 0.5 & 0.1 & 6.2 & 4.5 & 10.2 & 7.8 & 50.2 & 3.6 & 10.4 & 6.6 & 53 \\
\hline 2001 & 1575.7 & 0.6 & 0.3 & 12.4 & 6.4 & 13.2 & 8.8 & 41.2 & 1.5 & 10.9 & 4.6 & 58 \\
\hline 2002 & 1549.5 & 1.5 & 0.3 & 12.1 & 8.4 & 12.4 & 8.2 & 39.7 & 1.3 & 11.8 & 4.3 & 54 \\
\hline 2003 & 1360.1 & 1.5 & 0.4 & 15.2 & 8.5 & 10.5 & 6 & 35.1 & 2 & 15.9 & 4.7 & 59 \\
\hline 2004 & 1230.4 & 0.5 & 0.1 & 12.2 & 9 & 12.7 & 6.9 & 33.4 & 2.6 & 17.6 & 5 & 41 \\
\hline 2005 & 1324.0 & 0.8 & 0.1 & 4.6 & 12.4 & 13.3 & 6.9 & 37.9 & 2.3 & 17.6 & 4.2 & 37 \\
\hline 2006 & 1566.2 & 0.2 & 0.2 & 3 & 10.9 & 12.5 & 5.5 & 39 & 2.2 & 21.3 & 5.3 & 49 \\
\hline 2007 & 1894.6 & 0.9 & 0.2 & 3.3 & 12.4 & 13.4 & 6.9 & 36.2 & 3.9 & 16.4 & 6.4 & 44 \\
\hline 2008 & 1890.4 & 2.4 & 0.5 & 13.1 & 9.1 & 18.6 & 7 & 33.4 & 3 & 9.1 & 3.8 & 47 \\
\hline
\end{tabular}

${ }^{1}$ Prior to 1994, bank notes are included in other assets.

${ }^{2}$ Prior to 1998, corporate notes are included in other assets.

${ }^{3}$ Other assets include banker's acceptances, municipal securities, and cash reserves.

Note: Data for funds that invest primarily in other mutual funds were excluded from the series. Source: ICI Factbook, 2009 


\begin{tabular}{|c|c|c|c|c|c|c|c|}
\hline \multicolumn{8}{|c|}{ Panel A: Prime Institutional Funds } \\
\hline \multirow[b]{2}{*}{ Variable } & \multicolumn{4}{|c|}{ Coefficients with Lags } & \multicolumn{3}{|c|}{ Coefficients without Lags } \\
\hline & (Baseline) & (Pre-Crisis) & (Crisis) & (Post-Crisis) & (Pre-Crisis) & (Crisis) & (Post-Crisis) \\
\hline \multirow{2}{*}{$y_{i, t-1}-\bar{y}_{t-1}>0$} & -0.0444 & 0.3169 & 0.2344 & -0.0402 & - & - & - \\
\hline & {$[0.002]$} & {$[0.017]$} & {$[0.069]$} & {$[0.158]$} & - & - & - \\
\hline \multirow{2}{*}{$y_{i, t-1}-\bar{y}_{t-1}<0$} & -0.0175 & 0.2831 & 0.0606 & 0.1059 & - & - & - \\
\hline & {$[0.339]$} & {$[0.054]$} & {$[0.416]$} & {$[0.005]$} & - & - & - \\
\hline \multirow[t]{2}{*}{$A V G Y I E L D$} & 0.0001 & -0.0011 & -0.0119 & -0.0006 & -0.0012 & -0.0130 & -0.0007 \\
\hline & {$[0.341]$} & {$[0.109]$} & {$[0.001]$} & {$[0.249]$} & {$[0.159]$} & {$[0.002]$} & {$[0.234]$} \\
\hline \multirow[t]{2}{*}{$E X P R$} & -0.0001 & 0.0012 & 0.0083 & 0.0016 & 0.0011 & 0.0097 & 0.0019 \\
\hline & {$[0.336]$} & {$[0.185]$} & {$[0.018]$} & {$[0.016]$} & {$[0.313]$} & {$[0.025]$} & {$[0.009]$} \\
\hline \multirow[t]{2}{*}{ FLOWSTDEV } & 0.0013 & -0.0025 & -0.0035 & 0.0002 & -0.0028 & -0.0041 & -0.0004 \\
\hline & {$[0.000]$} & {$[0.061]$} & {$[0.158]$} & {$[0.415]$} & {$[0.083]$} & {$[0.113]$} & {$[0.378]$} \\
\hline \multirow[t]{2}{*}{ PIPERC } & -0.0003 & -0.0031 & -0.0070 & -0.0009 & -0.0036 & -0.0083 & -0.0010 \\
\hline & {$[0.083]$} & {$[0.051]$} & {$[0.037]$} & {$[0.080]$} & {$[0.048]$} & {$[0.035]$} & {$[0.085]$} \\
\hline \multirow[t]{2}{*}{$L O G T N A$} & 0.0005 & -0.0059 & -0.0209 & -0.0011 & -0.0075 & -0.0255 & -0.0010 \\
\hline & {$[0.001]$} & {$[0.000]$} & {$[0.000]$} & [0.138] & {$[0.000]$} & {$[0.000]$} & {$[0.145]$} \\
\hline \multicolumn{8}{|c|}{ Panel B: Prime Retail Funds } \\
\hline \multirow[b]{2}{*}{ Variable } & & Coefficien & with Lags & & Coef & ients with & Lags \\
\hline & (Baseline) & (Pre-Crisis) & (Crisis) & (Post-Crisis) & (Pre-Crisis) & (Crisis) & (Post-Crisis) \\
\hline \multirow{2}{*}{$y_{i, t-1}-\bar{y}_{t-1}>0$} & -0.4277 & -0.5703 & -0.3988 & -0.2841 & - & - & - \\
\hline & {$[0.000]$} & {$[0.039]$} & {$[0.096]$} & {$[0.041]$} & - & - & - \\
\hline \multirow{2}{*}{$y_{i, t-1}-\bar{y}_{t-1}<0$} & -0.1075 & -0.2206 & -0.5006 & -0.1331 & - & - & - \\
\hline & {$[0.085]$} & {$[0.183]$} & {$[0.317]$} & {$[0.117]$} & - & - & - \\
\hline \multirow[t]{2}{*}{$A V G Y I E L D$} & 0.0004 & 0.0017 & -0.0003 & -0.0003 & 0.0012 & -0.0013 & -0.0002 \\
\hline & {$[0.035]$} & {$[0.290]$} & {$[0.383]$} & {$[0.283]$} & {$[0.264]$} & {$[0.228]$} & {$[0.320]$} \\
\hline \multirow[t]{2}{*}{$E X P R$} & -0.0002 & -0.0001 & 0.0012 & 0.0008 & 0.0003 & 0.0004 & 0.0007 \\
\hline & {$[0.150]$} & {$[0.507]$} & {$[0.422]$} & {$[0.214]$} & {$[0.347]$} & {$[0.450]$} & {$[0.192]$} \\
\hline \multirow[t]{2}{*}{ FLOWSTDEV } & 0.0035 & 0.0049 & 0.0024 & 0.0007 & 0.0016 & -0.0004 & 0.0001 \\
\hline & {$[0.004]$} & {$[0.127]$} & {$[0.393]$} & {$[0.318]$} & {$[0.252]$} & {$[0.444]$} & {$[0.416]$} \\
\hline \multirow[t]{2}{*}{ PIPERC } & -0.0001 & 0.0005 & 0.0029 & 0.0004 & -0.0004 & 0.0041 & 0.0004 \\
\hline & {$[0.313]$} & {$[0.432]$} & {$[0.326]$} & {$[0.281]$} & {$[0.445]$} & {$[0.320]$} & {$[0.268]$} \\
\hline \multirow[t]{2}{*}{$L O G T N A$} & -0.0003 & -0.0027 & -0.0069 & -0.0023 & -0.0014 & -0.0065 & -0.0018 \\
\hline & {$[0.294]$} & {$[0.137]$} & {$[0.004]$} & {$[0.002]$} & {$[0.179]$} & {$[0.000]$} & {$[0.000]$} \\
\hline
\end{tabular}

Table 5: Fund-Level Panel Regressions - OLS Coefficients

This table presents the coefficients from an OLS regression with time dummies, where the slope coefficients vary over three different periods in 2008: 9/10-9/16, 9/17-9/19, and 9/22-10/17, respectively. Time dummies are omitted for brevity. Numbers in brackets are one-sided bootstrapped p-values clustered at the fund level. 


\begin{tabular}{|c|c|c|c|c|}
\hline \multirow[b]{2}{*}{ Variable } & \multicolumn{4}{|c|}{ Common Shock } \\
\hline & (Baseline) & (Pre-Crisis) & (Crisis) & (Post-Crisis) \\
\hline \multirow{2}{*}{$y_{i, t-1}-\bar{y}_{t-1}>0$} & -0.0270 & 0.1124 & 0.2260 & -0.0125 \\
\hline & {$[0.070]$} & {$[0.019]$} & {$[0.014]$} & {$[0.345]$} \\
\hline \multirow{2}{*}{$y_{i, t-1}-\bar{y}_{t-1}<0$} & -0.0057 & 0.2369 & 0.5761 & 0.0796 \\
\hline & {$[0.335]$} & {$[0.032]$} & {$[0.043]$} & {$[0.005]$} \\
\hline \multirow[t]{2}{*}{$A V G Y I E L D$} & 0.0002 & -0.0007 & -0.0064 & -0.0007 \\
\hline & [0.128] & {$[0.080]$} & {$[0.000]$} & {$[0.022]$} \\
\hline \multirow[t]{2}{*}{$E X P R$} & -0.0000 & 0.0009 & 0.0033 & 0.0012 \\
\hline & {$[0.348]$} & {$[0.049]$} & {$[0.054]$} & {$[0.003]$} \\
\hline \multirow[t]{2}{*}{ FLOWSTDEV } & 0.0001 & -0.0002 & -0.0040 & -0.0011 \\
\hline & [0.284] & [0.343] & [0.117] & {$[0.086]$} \\
\hline \multirow[t]{2}{*}{ PIPERC } & -0.0002 & -0.0006 & -0.0002 & -0.0005 \\
\hline & [0.066] & {$[0.206]$} & {$[0.365]$} & {$[0.194]$} \\
\hline \multirow[t]{2}{*}{$L O G T N A$} & 0.0002 & -0.0026 & -0.0133 & -0.0013 \\
\hline & {$[0.019]$} & {$[0.000]$} & {$[0.000]$} & {$[0.016]$} \\
\hline \multirow[b]{2}{*}{ Variable } & \multicolumn{4}{|c|}{ Left Tail Exposure } \\
\hline & (Baseline) & (Pre-Crisis) & (Crisis) & (Post-Crisis) \\
\hline \multirow[t]{2}{*}{$y_{i, t-1}-\bar{y}_{t-1}>0$} & 0.1064 & -0.0211 & 0.0038 & 0.0545 \\
\hline & {$[0.000]$} & {$[0.405]$} & {$[0.572]$} & {$[0.003]$} \\
\hline \multirow[t]{2}{*}{$\left|y_{i, t-1}-\bar{y}_{t-1}<0\right|$} & 0.0693 & 0.0369 & -0.0154 & 0.0819 \\
\hline & {$[0.000]$} & {$[0.106]$} & [0.284] & {$[0.003]$} \\
\hline \multirow[t]{2}{*}{$A V G Y I E L D$} & -0.0217 & 0.1283 & 0.2314 & 0.0490 \\
\hline & {$[0.334]$} & {$[0.080]$} & {$[0.095]$} & {$[0.238]$} \\
\hline \multirow[t]{2}{*}{$E X P R$} & -0.1978 & -0.5379 & -0.2021 & -0.2998 \\
\hline & {$[0.012]$} & {$[0.004]$} & {$[0.144]$} & {$[0.002]$} \\
\hline \multirow[t]{2}{*}{ FLOW STDEV } & 0.5162 & 0.4453 & 0.3451 & 0.3044 \\
\hline & {$[0.000]$} & {$[0.003]$} & {$[0.003]$} & {$[0.000]$} \\
\hline \multirow[t]{2}{*}{ PIPERC } & 0.0588 & 0.1092 & 0.2902 & 0.0818 \\
\hline & [0.089] & {$[0.107]$} & {$[0.010]$} & {$[0.106]$} \\
\hline \multirow[t]{2}{*}{$L O G T N A$} & -0.0040 & 0.0507 & 0.0632 & -0.1031 \\
\hline & {$[0.625]$} & {$[0.188]$} & {$[0.161]$} & {$[0.063]$} \\
\hline \multirow[b]{2}{*}{ Variable } & \multicolumn{4}{|c|}{ Right Tail Exposure } \\
\hline & (Baseline) & (Pre-Crisis) & (Crisis) & (Post-Crisis) \\
\hline \multirow[t]{2}{*}{$y_{i, t-1}-\bar{y}_{t-1}>0$} & 0.0108 & 0.1168 & -0.0066 & 0.0591 \\
\hline & {$[0.125]$} & [0.098] & [0.322] & {$[0.068]$} \\
\hline \multirow[t]{2}{*}{$\left|y_{i, t-1}-\bar{y}_{t-1}<0\right|$} & 0.0595 & 0.0716 & 0.0584 & 0.0538 \\
\hline & {$[0.000]$} & [0.075] & [0.135] & [0.003] \\
\hline \multirow[t]{2}{*}{$A V G Y I E L D$} & -0.0229 & -0.0121 & 0.1080 & 0.0090 \\
\hline & {$[0.332]$} & {$[0.456]$} & {$[0.119]$} & {$[0.559]$} \\
\hline$E X P R$ & -0.2059 & -0.0918 & -0.0290 & -0.1761 \\
\hline & {$[0.000]$} & {$[0.180]$} & {$[0.177]$} & {$[0.043]$} \\
\hline FLOW STDEV & 0.6262 & 0.5556 & 0.4517 & 0.4205 \\
\hline & {$[0.000]$} & {$[0.002]$} & {$[0.007]$} & {$[0.000]$} \\
\hline PIPERC & 0.0924 & 0.1509 & 0.0057 & 0.0486 \\
\hline & {$[0.026]$} & {$[0.066]$} & {$[0.356]$} & {$[0.407]$} \\
\hline LOGTNA & 0.0551 & 0.0846 & 0.2846 & -0.0374 \\
\hline & {$[0.156]$} & {$[0.268]$} & {$[0.064]$} & {$[0.312]$} \\
\hline
\end{tabular}

Table 6: Fund-Level Panel Quantile Regressions - Prime Institutional

This table presents the coefficients from estimating equation (2). $\beta_{0}, \beta_{1}$, and $\beta_{2}$ vary over three different periods in 2008: 9/10-9/16,9/17-9/19, and 9/22-10/17, respectively. Time dummies are omitted for brevity. Numbers in brackets are one-sided bootstrapped p-values clustered at the fund level. Coefficients for lagged variables have been divided by 100 for spacings 1 and 2 . 


\begin{tabular}{|c|c|c|c|c|}
\hline \multirow[b]{2}{*}{ Variable } & \multicolumn{4}{|c|}{ Common Shock } \\
\hline & (Baseline) & (Pre-Crisis) & (Crisis) & (Post-Crisis) \\
\hline \multirow{2}{*}{$y_{i, t-1}-\bar{y}_{t-1}>0$} & -0.1023 & -0.5352 & 0.1693 & -0.0030 \\
\hline & {$[0.000]$} & {$[0.138]$} & {$[0.016]$} & {$[0.348]$} \\
\hline \multirow{2}{*}{$y_{i, t-1}-\bar{y}_{t-1}<0$} & -0.0143 & -0.0391 & 0.0382 & -0.0275 \\
\hline & {$[0.336]$} & {$[0.470]$} & {$[0.219]$} & [0.248] \\
\hline \multirow[t]{2}{*}{$A V G Y I E L D$} & 0.0001 & -0.0001 & -0.0014 & -0.0004 \\
\hline & {$[0.152]$} & {$[0.297]$} & [0.060] & {$[0.154]$} \\
\hline \multirow[t]{2}{*}{$E X P R$} & -0.0000 & 0.0006 & -0.0006 & 0.0007 \\
\hline & {$[0.263]$} & {$[0.005]$} & {$[0.249]$} & {$[0.024]$} \\
\hline \multirow{2}{*}{ FLOWSTDEV } & 0.0000 & 0.0001 & -0.0018 & -0.0004 \\
\hline & [0.394] & {$[0.347]$} & [0.140] & {$[0.226]$} \\
\hline \multirow[t]{2}{*}{ PIPERC } & -0.0000 & -0.0001 & 0.0002 & -0.0000 \\
\hline & [0.277] & [0.270] & {$[0.382]$} & {$[0.406]$} \\
\hline \multirow[t]{2}{*}{$L O G T N A$} & -0.0000 & 0.0000 & -0.0018 & -0.0015 \\
\hline & {$[0.182]$} & {$[0.456]$} & {$[0.000]$} & {$[0.000]$} \\
\hline \multirow[b]{2}{*}{ Variable } & \multicolumn{4}{|c|}{ Left Tail Exposure } \\
\hline & (Baseline) & (Pre-Crisis) & (Crisis) & (Post-Crisis) \\
\hline \multirow[t]{2}{*}{$y_{i, t-1}-\bar{y}_{t-1}>0$} & 0.2289 & 0.0330 & 0.0660 & 0.1263 \\
\hline & {$[0.000]$} & {$[0.299]$} & {$[0.181]$} & {$[0.006]$} \\
\hline \multirow[t]{2}{*}{$\left|y_{i, t-1}-\bar{y}_{t-1}<0\right|$} & 0.1338 & 0.1252 & 0.1325 & 0.1815 \\
\hline & {$[0.001]$} & {$[0.104]$} & {$[0.141]$} & {$[0.013]$} \\
\hline \multirow[t]{2}{*}{$A V G Y I E L D$} & -0.1295 & -0.0678 & -0.2538 & -0.1005 \\
\hline & {$[0.030]$} & {$[0.280]$} & {$[0.142]$} & {$[0.216]$} \\
\hline \multirow[t]{2}{*}{$E X P R$} & 0.0283 & -0.0635 & 0.0973 & -0.0177 \\
\hline & {$[0.257]$} & {$[0.435]$} & {$[0.353]$} & {$[0.643]$} \\
\hline \multirow[t]{2}{*}{ FLOWSTDEV } & 0.3241 & 0.7901 & 0.2404 & 0.3734 \\
\hline & {$[0.002]$} & {$[0.000]$} & {$[0.262]$} & {$[0.004]$} \\
\hline \multirow[t]{2}{*}{ PIPERC } & 0.0977 & -0.0208 & 0.3245 & 0.0564 \\
\hline & {$[0.099]$} & [0.568] & [0.158] & {$[0.275]$} \\
\hline \multirow[t]{2}{*}{$L O G T N A$} & -0.1738 & -0.1003 & 0.2077 & -0.0829 \\
\hline & {$[0.010]$} & {$[0.130]$} & {$[0.118]$} & {$[0.102]$} \\
\hline \multirow[b]{2}{*}{ Variable } & \multicolumn{4}{|c|}{ Right Tail Exposure } \\
\hline & (Baseline) & (Pre-Crisis) & (Crisis) & (Post-Crisis) \\
\hline \multirow[t]{2}{*}{$y_{i, t-1}-\bar{y}_{t-1}>0$} & 0.0956 & 0.3086 & -0.1047 & 0.1491 \\
\hline & {$[0.003]$} & {$[0.034]$} & [0.492] & {$[0.028]$} \\
\hline \multirow[t]{2}{*}{$\left|y_{i, t-1}-\bar{y}_{t-1}<0\right|$} & 0.1104 & -0.0321 & 0.0703 & 0.0674 \\
\hline & {$[0.003]$} & {$[0.387]$} & [0.150] & {$[0.057]$} \\
\hline \multirow[t]{2}{*}{$A V G Y I E L D$} & -0.1723 & -0.0496 & -0.1062 & -0.1438 \\
\hline & {$[0.002]$} & {$[0.286]$} & {$[0.361]$} & {$[0.025]$} \\
\hline$E X P R$ & 0.0688 & 0.1649 & 0.0236 & 0.0688 \\
\hline & {$[0.142]$} & {$[0.157]$} & {$[0.367]$} & {$[0.166]$} \\
\hline FLOW STDEV & 0.5962 & 0.8579 & 0.0584 & 0.3910 \\
\hline & {$[0.000]$} & {$[0.022]$} & {$[0.299]$} & {$[0.007]$} \\
\hline PIPERC & 0.0968 & 0.1494 & -0.0870 & 0.0618 \\
\hline & {$[0.091]$} & [0.139] & [0.364] & {$[0.178]$} \\
\hline LOGTNA & -0.1875 & -0.2080 & -0.3070 & -0.0479 \\
\hline & {$[0.008]$} & {$[0.116]$} & {$[0.112]$} & {$[0.212]$} \\
\hline
\end{tabular}

Table 7: Fund-Level Panel Quantile Regressions - Prime Retail

This table presents the coefficients from estimating equation (2). $\beta_{0}, \beta_{1}$, and $\beta_{2}$ vary over three different periods in 2008: 9/10-9/16,9/17-9/19, and 9/22-10/17, respectively. Time dummies are omitted for brevity. Numbers in brackets are one-sided bootstrapped p-values clustered at the fund level. Coefficients for lagged variables have been divided by 100 for spacings 1 and 2 . 


\begin{tabular}{|c|c|c|c|c|}
\hline \multirow[b]{2}{*}{ Variable } & \multicolumn{4}{|c|}{ Common Shock } \\
\hline & (Baseline) & (Pre-Crisis) & (Crisis) & (Post-Crisis) \\
\hline \multirow{2}{*}{$y_{i, t-1}>0$} & -0.0191 & 0.0739 & 0.0976 & -0.0217 \\
\hline & {$[0.113]$} & {$[0.194]$} & {$[0.396]$} & {$[0.243]$} \\
\hline \multirow{2}{*}{$y_{i, t-1}<0$} & -0.0182 & 0.2648 & 0.4314 & 0.0813 \\
\hline & {$[0.111]$} & {$[0.000]$} & {$[0.000]$} & {$[0.001]$} \\
\hline \multirow[t]{2}{*}{$A V G Y I E L D$} & 0.0002 & -0.0004 & -0.0062 & -0.0006 \\
\hline & {$[0.153]$} & {$[0.104]$} & {$[0.000]$} & {$[0.041]$} \\
\hline \multirow[t]{2}{*}{$E X P R$} & -0.0000 & 0.0005 & 0.0022 & 0.0011 \\
\hline & {$[0.414]$} & {$[0.068]$} & {$[0.065]$} & {$[0.001]$} \\
\hline \multirow[t]{2}{*}{ FLOWSTDEV } & 0.0000 & -0.0001 & -0.0039 & -0.0010 \\
\hline & [0.328] & {$[0.594]$} & {$[0.150]$} & {$[0.116]$} \\
\hline \multirow[t]{2}{*}{ PIPERC } & -0.0002 & -0.0004 & -0.0003 & -0.0005 \\
\hline & {$[0.053]$} & {$[0.236]$} & {$[0.384]$} & {$[0.156]$} \\
\hline \multirow[t]{2}{*}{$L O G T N A$} & 0.0002 & -0.0025 & -0.0111 & -0.0012 \\
\hline & {$[0.021]$} & {$[0.001]$} & {$[0.000]$} & {$[0.011]$} \\
\hline \multirow[b]{2}{*}{ Variable } & \multicolumn{4}{|c|}{ Left Tail Exposure } \\
\hline & (Baseline) & (Pre-Crisis) & (Crisis) & (Post-Crisis) \\
\hline \multirow[t]{2}{*}{$y_{i, t-1}>0$} & 0.1122 & 0.0764 & 0.0259 & 0.0605 \\
\hline & {$[0.000]$} & {$[0.182]$} & {$[0.408]$} & {$[0.004]$} \\
\hline \multirow[t]{2}{*}{$\left|y_{i, t-1}<0\right|$} & 0.0789 & 0.0680 & -0.0110 & 0.0699 \\
\hline & {$[0.000]$} & {$[0.019]$} & {$[0.413]$} & {$[0.003]$} \\
\hline \multirow[t]{2}{*}{$A V G Y I E L D$} & -0.0232 & 0.1392 & 0.2110 & 0.0196 \\
\hline & {$[0.292]$} & {$[0.101]$} & {$[0.072]$} & {$[0.268]$} \\
\hline \multirow[t]{2}{*}{$E X P R$} & -0.2051 & -0.4962 & -0.2474 & -0.3179 \\
\hline & {$[0.010]$} & {$[0.002]$} & {$[0.096]$} & {$[0.002]$} \\
\hline \multirow[t]{2}{*}{ FLOWSTDEV } & 0.4873 & 0.3560 & 0.3061 & 0.2688 \\
\hline & {$[0.000]$} & {$[0.005]$} & {$[0.029]$} & {$[0.000]$} \\
\hline \multirow[t]{2}{*}{ PIPERC } & 0.0558 & 0.1078 & 0.2529 & 0.0852 \\
\hline & {$[0.089]$} & {$[0.175]$} & {$[0.008]$} & {$[0.090]$} \\
\hline \multirow[t]{2}{*}{$L O G T N A$} & -0.0182 & 0.1009 & 0.1131 & -0.1238 \\
\hline & {$[0.562]$} & {$[0.150]$} & {$[0.211]$} & {$[0.055]$} \\
\hline \multirow[b]{2}{*}{ Variable } & \multicolumn{4}{|c|}{ Right Tail Exposure } \\
\hline & (Baseline) & (Pre-Crisis) & (Crisis) & (Post-Crisis) \\
\hline \multirow[t]{2}{*}{$y_{i, t-1}>0$} & 0.0109 & 0.1282 & -0.0539 & 0.0741 \\
\hline & {$[0.065]$} & {$[0.144]$} & {$[0.440]$} & {$[0.034]$} \\
\hline \multirow[t]{2}{*}{$\left|y_{i, t-1}<0\right|$} & 0.0672 & 0.0444 & 0.0407 & 0.0578 \\
\hline & {$[0.000]$} & {$[0.136]$} & {$[0.030]$} & {$[0.003]$} \\
\hline \multirow[t]{2}{*}{$A V G Y I E L D$} & -0.0272 & -0.0333 & 0.1599 & -0.0156 \\
\hline & {$[0.312]$} & {$[0.397]$} & {$[0.140]$} & {$[0.366]$} \\
\hline$E X P R$ & -0.2046 & -0.0489 & -0.0489 & -0.1666 \\
\hline & {$[0.001]$} & {$[0.204]$} & {$[0.175]$} & {$[0.035]$} \\
\hline FLOWSTDEV & 0.6113 & 0.5624 & 0.5306 & 0.4236 \\
\hline & {$[0.000]$} & {$[0.004]$} & {$[0.006]$} & {$[0.000]$} \\
\hline PIPERC & 0.0934 & 0.1881 & -0.0049 & 0.0140 \\
\hline & {$[0.021]$} & {$[0.046]$} & {$[0.558]$} & {$[0.425]$} \\
\hline LOGTNA & 0.0471 & 0.0740 & 0.2408 & -0.0336 \\
\hline & [0.178] & [0.333] & {$[0.062]$} & {$[0.327]$} \\
\hline
\end{tabular}

Table 8: Fund-Level Panel Quantile Regression - Prime Institutional with Alternative Lag Specification

This table presents the coefficients from estimating equation (2). $\beta_{0}, \beta_{1}$, and $\beta_{2}$ vary over three different periods in 2008: 9/10-9/16,9/17-9/19, and 9/22-10/17, respectively. Time dummies are omitted for brevity. Numbers in brackets are one-sided bootstrapped p-values clustered at the fund level. Coefficients for lagged variables have been divided by 100 for spacings 1 and 2 . 


\begin{tabular}{|c|c|c|c|c|}
\hline \multirow[b]{2}{*}{ Variable } & \multicolumn{4}{|c|}{ Common Shock } \\
\hline & (Baseline) & (Pre-Crisis) & (Crisis) & (Post-Crisis) \\
\hline \multirow[t]{2}{*}{$y_{i, t-1}-\bar{y}_{t-1}>0$} & -0.0273 & 0.0951 & 0.2055 & 0.0012 \\
\hline & {$[0.068]$} & {$[0.013]$} & {$[0.023]$} & {$[0.617]$} \\
\hline \multirow[t]{2}{*}{$y_{i, t-1}-\bar{y}_{t-1}<0$} & -0.0057 & 0.2390 & 0.5723 & 0.0813 \\
\hline & {$[0.353]$} & {$[0.039]$} & {$[0.056]$} & {$[0.007]$} \\
\hline \multirow[t]{2}{*}{$A V G Y I E L D$} & 0.0002 & -0.0006 & -0.0078 & -0.0007 \\
\hline & {$[0.126]$} & {$[0.090]$} & {$[0.000]$} & {$[0.034]$} \\
\hline \multirow[t]{2}{*}{$E X P R$} & -0.0000 & 0.0007 & 0.0033 & 0.0012 \\
\hline & {$[0.363]$} & {$[0.052]$} & {$[0.058]$} & {$[0.002]$} \\
\hline \multirow{2}{*}{ FLOWSTDEV } & 0.0001 & -0.0002 & -0.0033 & -0.0013 \\
\hline & {$[0.282]$} & {$[0.297]$} & {$[0.117]$} & {$[0.070]$} \\
\hline \multirow[t]{2}{*}{ PIPERC } & -0.0002 & -0.0003 & -0.0001 & -0.0002 \\
\hline & {$[0.086]$} & {$[0.283]$} & {$[0.463]$} & [0.323] \\
\hline \multirow[t]{2}{*}{$L O G T N A$} & 0.0002 & -0.0028 & -0.0127 & -0.0012 \\
\hline & {$[0.045]$} & {$[0.000]$} & {$[0.000]$} & {$[0.016]$} \\
\hline \multirow[t]{2}{*}{$M U L T C A T$} & 0.0000 & -0.0001 & 0.0019 & 0.0010 \\
\hline & {$[0.476]$} & {$[0.484]$} & {$[0.130]$} & {$[0.040]$} \\
\hline \multirow[t]{2}{*}{ LAGOTHER } & 0.0003 & 0.0011 & 0.0002 & 0.0003 \\
\hline & {$[0.021]$} & {$[0.041]$} & {$[0.247]$} & {$[0.343]$} \\
\hline \multirow[b]{2}{*}{ Variable } & \multicolumn{4}{|c|}{ Left Tail Exposure } \\
\hline & (Baseline) & (Pre-Crisis) & (Crisis) & (Post-Crisis) \\
\hline \multirow[t]{2}{*}{$y_{i, t-1}-\bar{y}_{t-1}>0$} & 0.1073 & -0.0175 & 0.0100 & 0.0373 \\
\hline & {$[0.000]$} & {$[0.387]$} & {$[0.485]$} & {$[0.013]$} \\
\hline \multirow[t]{2}{*}{$\left|y_{i, t-1}-\bar{y}_{t-1}<0\right|$} & 0.0699 & 0.0390 & -0.0173 & 0.0700 \\
\hline & {$[0.000]$} & {$[0.150]$} & {$[0.319]$} & {$[0.010]$} \\
\hline \multirow[t]{2}{*}{$A V G Y I E L D$} & -0.0191 & 0.1573 & 0.2337 & 0.0575 \\
\hline & {$[0.360]$} & {$[0.082]$} & {$[0.097]$} & {$[0.169]$} \\
\hline \multirow[t]{2}{*}{$E X P R$} & -0.1978 & -0.3824 & -0.1960 & -0.3044 \\
\hline & {$[0.015]$} & {$[0.013]$} & {$[0.218]$} & {$[0.000]$} \\
\hline FLOWSTDEV & 0.5108 & 0.4688 & 0.4026 & 0.3201 \\
\hline & {$[0.000]$} & {$[0.001]$} & {$[0.001]$} & {$[0.000]$} \\
\hline PIPERC & 0.0525 & 0.1207 & 0.3097 & 0.0760 \\
\hline & {$[0.108]$} & {$[0.141]$} & {$[0.023]$} & {$[0.192]$} \\
\hline LOGTNA & -0.0069 & 0.1575 & 0.1259 & -0.1222 \\
\hline & {$[0.639]$} & {$[0.168]$} & {$[0.105]$} & {$[0.047]$} \\
\hline$M U L T C A T$ & -0.0265 & -0.1041 & 0.0487 & -0.0900 \\
\hline & {$[0.213]$} & {$[0.120]$} & {$[0.405]$} & {$[0.066]$} \\
\hline LAGOTHER & 0.0212 & -0.0193 & -0.2457 & -0.0094 \\
\hline & {$[0.300]$} & {$[0.336]$} & {$[0.035]$} & {$[0.359]$} \\
\hline & & Right Ta & Exposure & \\
\hline Variable & (Baseline) & (Pre-Crisis) & (Crisis) & (Post-Crisis) \\
\hline$y_{i, t-1}-\bar{y}_{t-1}>0$ & 0.0120 & 0.1204 & -0.0163 & 0.0500 \\
\hline & {$[0.136]$} & {$[0.093]$} & {$[0.313]$} & {$[0.066]$} \\
\hline$\left|y_{i, t-1}-\bar{y}_{t-1}<0\right|$ & 0.0599 & 0.0660 & 0.0544 & 0.0516 \\
\hline & {$[0.000]$} & {$[0.073]$} & {$[0.149]$} & {$[0.004]$} \\
\hline$A V G Y I E L D$ & -0.0215 & 0.0016 & 0.1365 & 0.0075 \\
\hline & {$[0.310]$} & {$[0.476]$} & {$[0.139]$} & {$[0.517]$} \\
\hline$E X P R$ & -0.2006 & -0.0836 & -0.0371 & -0.1502 \\
\hline & {$[0.001]$} & {$[0.148]$} & {$[0.156]$} & {$[0.031]$} \\
\hline FLOWSTDEV & 0.6445 & 0.5120 & 0.4280 & 0.4628 \\
\hline & {$[0.000]$} & {$[0.002]$} & {$[0.011]$} & {$[0.000]$} \\
\hline PIPERC & 0.0749 & 0.1282 & 0.0312 & 0.0402 \\
\hline & {$[0.034]$} & {$[0.079]$} & {$[0.442]$} & {$[0.524]$} \\
\hline$L O G T N A$ & 0.0532 & 0.0672 & 0.2399 & -0.0525 \\
\hline & {$[0.156]$} & {$[0.261]$} & {$[0.071]$} & {$[0.325]$} \\
\hline$M U L T C A T$ & -0.0700 & -0.0586 & -0.0824 & -0.0730 \\
\hline & {$[0.078]$} & {$[0.313]$} & {$[0.154]$} & {$[0.089]$} \\
\hline LAGOTHER & -0.0005 & -0.1395 & 0.1350 & 0.0397 \\
\hline & {$[0.427]$} & {$[0.273]$} & {$[0.327]$} & {$[0.255]$} \\
\hline
\end{tabular}

Table 9: Fund-Level Panel Quantile Regression - Prime Institutional with Cross-Category Variables

This table presents the coefficients from estimating equation (2). $\beta_{0}, \beta_{1}$, and $\beta_{2}$ vary over three different periods in 2008: 9/10-9/16, 9/17-9/19, and 9/22-10/17, respectively. Time dummies are omitted for brevity. Numbers in brackets are one-sided bootstrapped p-values clustered at the fund level. Coefficients for lagged variables have been divided by 100 for spacings 1 and 2 . 


\begin{tabular}{|c|c|c|c|c|}
\hline \multirow[b]{2}{*}{ Variable } & \multicolumn{4}{|c|}{ Prime Institutional Funds } \\
\hline & (Baseline) & (Pre-Crisis) & (Crisis) & (Post-Crisis) \\
\hline \multirow{2}{*}{$y_{i, t-1}-\bar{y}_{t-1}>0$} & -0.0444 & 0.3191 & 0.2234 & -0.0393 \\
\hline & {$[0.001]$} & {$[0.015]$} & {$[0.114]$} & {$[0.173]$} \\
\hline \multirow{2}{*}{$y_{i, t-1}-\bar{y}_{t-1}<0$} & -0.0175 & 0.2759 & 0.0519 & 0.1037 \\
\hline & {$[0.346]$} & {$[0.072]$} & [0.421] & {$[0.007]$} \\
\hline \multirow[t]{2}{*}{$A V G Y I E L D$} & 0.0001 & -0.0012 & -0.0120 & -0.0006 \\
\hline & [0.303] & {$[0.124]$} & {$[0.004]$} & {$[0.246]$} \\
\hline \multirow[t]{2}{*}{$E X P R$} & -0.0001 & 0.0012 & 0.0083 & 0.0016 \\
\hline & {$[0.306]$} & [0.243] & {$[0.017]$} & {$[0.028]$} \\
\hline \multirow[t]{2}{*}{ FLOWSTDEV } & 0.0013 & -0.0027 & -0.0039 & 0.0001 \\
\hline & {$[0.000]$} & {$[0.058]$} & [0.148] & {$[0.457]$} \\
\hline \multirow[t]{2}{*}{ PIPERC } & -0.0002 & -0.0028 & -0.0066 & -0.0007 \\
\hline & {$[0.075]$} & {$[0.087]$} & {$[0.087]$} & {$[0.158]$} \\
\hline \multirow{2}{*}{$L O G T N A$} & 0.0005 & -0.0060 & -0.0214 & -0.0011 \\
\hline & {$[0.002]$} & {$[0.000]$} & {$[0.000]$} & {$[0.127]$} \\
\hline \multirow[t]{2}{*}{$M U L T C A T$} & 0.0000 & 0.0004 & -0.0012 & 0.0005 \\
\hline & {$[0.565]$} & {$[0.359]$} & {$[0.407]$} & [0.234] \\
\hline \multirow[t]{2}{*}{ LAGOTHER } & 0.0002 & 0.0013 & 0.0056 & 0.0003 \\
\hline & {$[0.048]$} & {$[0.099]$} & {$[0.014]$} & {$[0.278]$} \\
\hline \multirow[b]{2}{*}{ Variable } & \multicolumn{4}{|c|}{ Prime Retail Funds } \\
\hline & (Baseline) & (Pre-Crisis) & (Crisis) & (Post-Crisis) \\
\hline \multirow{2}{*}{$y_{i, t-1}-\bar{y}_{t-1}>0$} & -0.4281 & -0.5716 & -0.3848 & -0.2849 \\
\hline & {$[0.000]$} & {$[0.052]$} & [0.109] & {$[0.032]$} \\
\hline \multirow[t]{2}{*}{$y_{i, t-1}-\bar{y}_{t-1}<0$} & -0.1073 & -0.2192 & -0.5260 & -0.1355 \\
\hline & {$[0.099]$} & {$[0.185]$} & {$[0.302]$} & {$[0.120]$} \\
\hline \multirow[t]{2}{*}{$A V G Y I E L D$} & 0.0004 & 0.0019 & 0.0003 & -0.0002 \\
\hline & [0.092] & {$[0.241]$} & [0.505] & [0.346] \\
\hline \multirow[t]{2}{*}{$E X P R$} & -0.0002 & -0.0002 & 0.0011 & 0.0007 \\
\hline & [0.163] & {$[0.476]$} & [0.423] & [0.264] \\
\hline \multirow[t]{2}{*}{ FLOWSTDEV } & 0.0034 & 0.0048 & 0.0012 & 0.0009 \\
\hline & [0.001] & [0.133] & [0.497] & [0.269] \\
\hline \multirow[t]{2}{*}{ PIPERC } & -0.0003 & 0.0012 & 0.0054 & 0.0011 \\
\hline & {$[0.114]$} & [0.433] & {$[0.234]$} & {$[0.100]$} \\
\hline \multirow[t]{2}{*}{$L O G T N A$} & -0.0004 & -0.0030 & -0.0080 & -0.0024 \\
\hline & {$[0.245]$} & {$[0.160]$} & {$[0.007]$} & {$[0.000]$} \\
\hline \multirow[t]{2}{*}{$M U L T C A T$} & 0.0004 & 0.0003 & 0.0020 & -0.0010 \\
\hline & [0.107] & [0.494] & {$[0.276]$} & [0.114] \\
\hline \multirow[t]{2}{*}{ LAGOTHER } & -0.0004 & -0.0019 & -0.0070 & -0.0016 \\
\hline & {$[0.290]$} & {$[0.148]$} & {$[0.130]$} & {$[0.069]$} \\
\hline
\end{tabular}

Table 10: Fund-Level Panel Regressions - OLS Coefficients with Cross-Category Variables

This table presents the coefficients from an OLS regression with time dummies, where the slope coefficients vary over three different periods in 2008: 9/10-9/16,9/17-9/19, and 9/22-10/17, respectively. Time dummies are omitted for brevity. Numbers in brackets are one-sided bootstrapped p-values clustered at the fund level. 


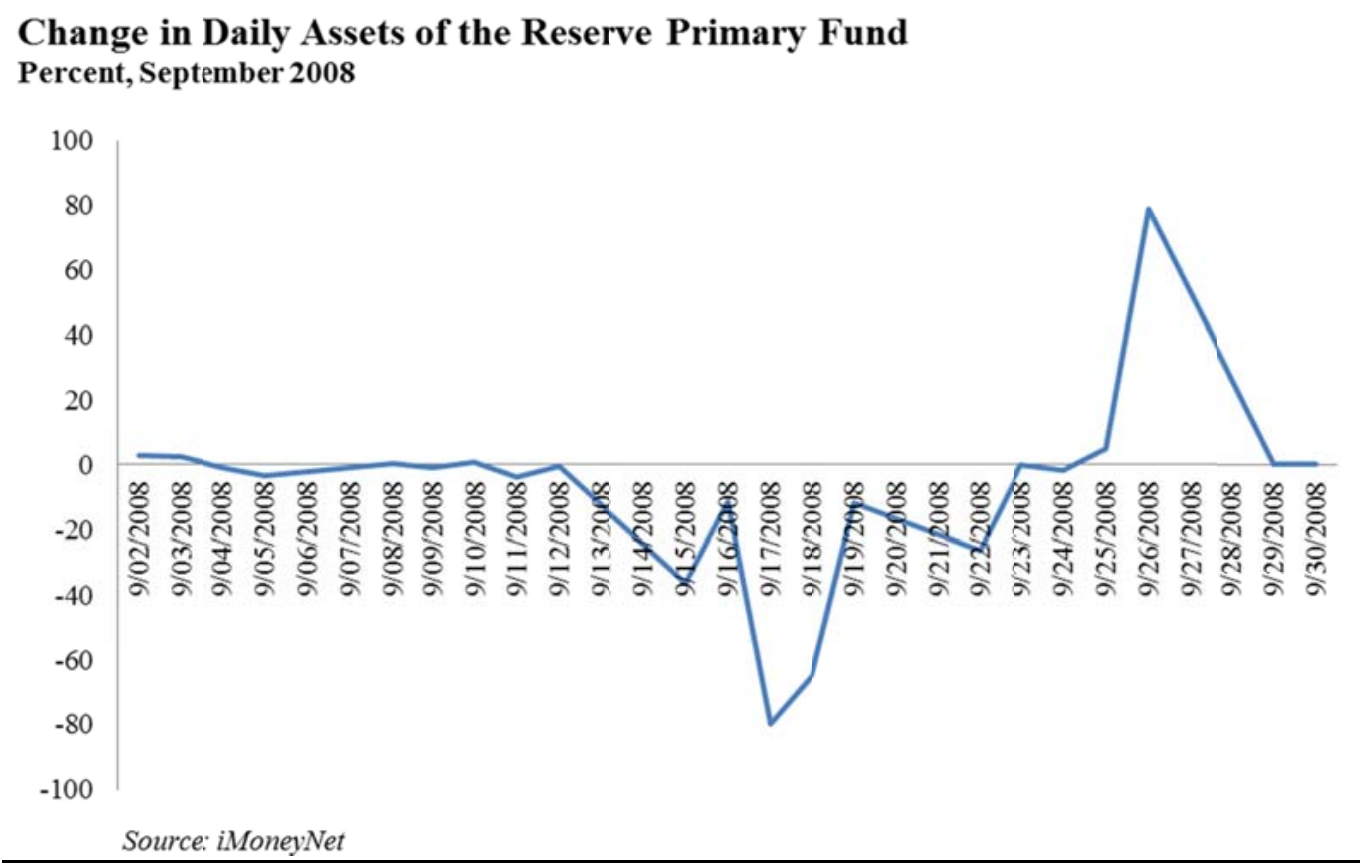

\section{Change in Daily Assets of Money Market Funds}

Percent, September 2008

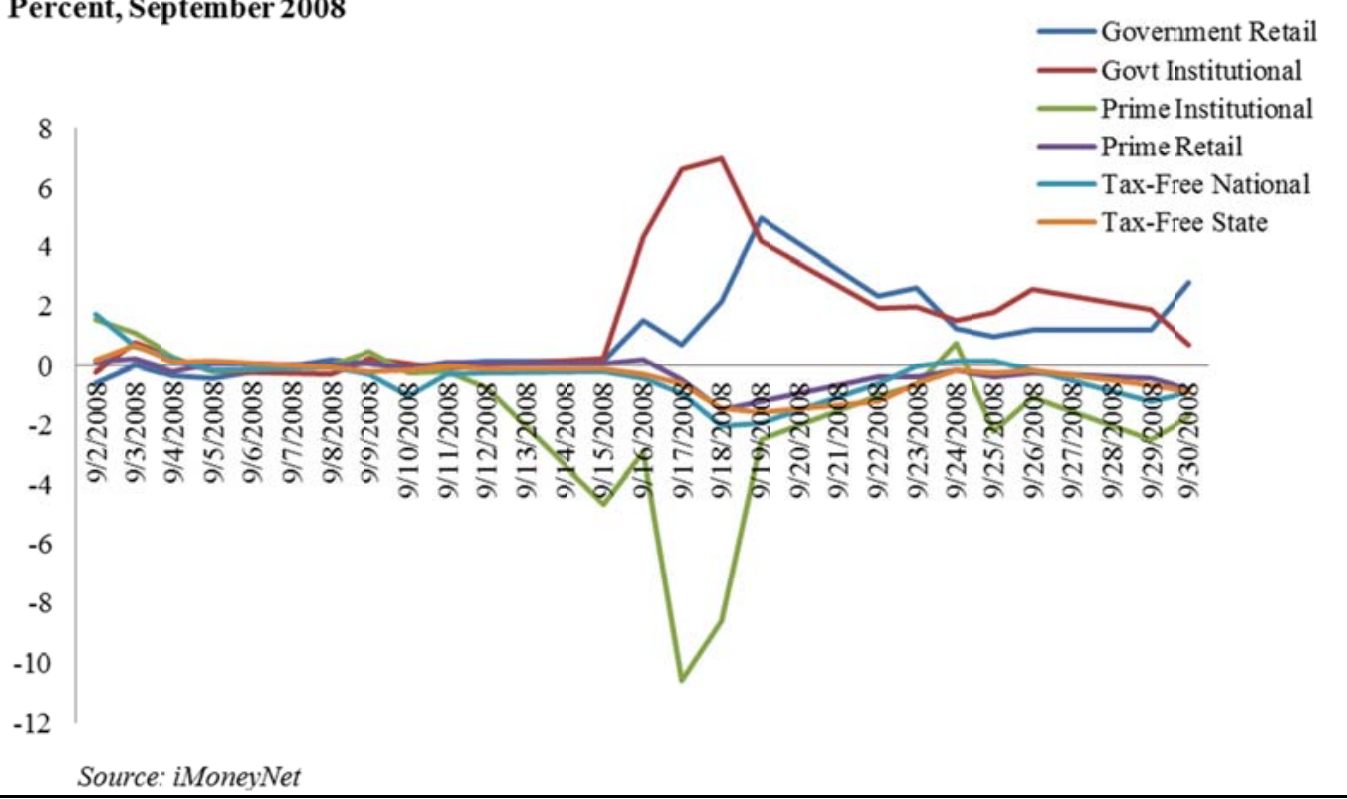

Figure 1: Daily Flows to/from the Reserve Primary Fund in September 2008 (in \%) 


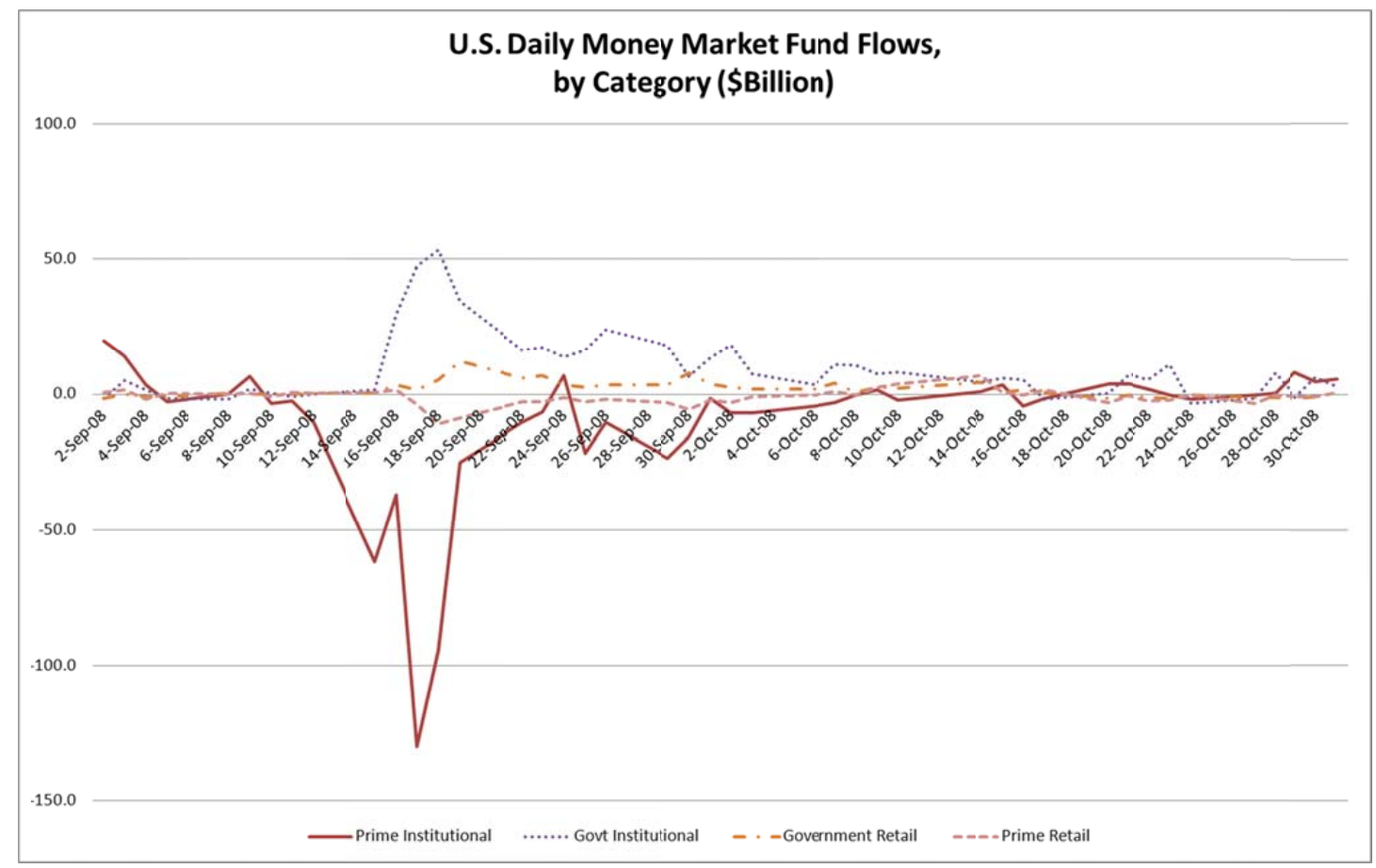

Figure 2: Daily Flows to/from Money Fund Categories in September 2008 (in \$Billions) 

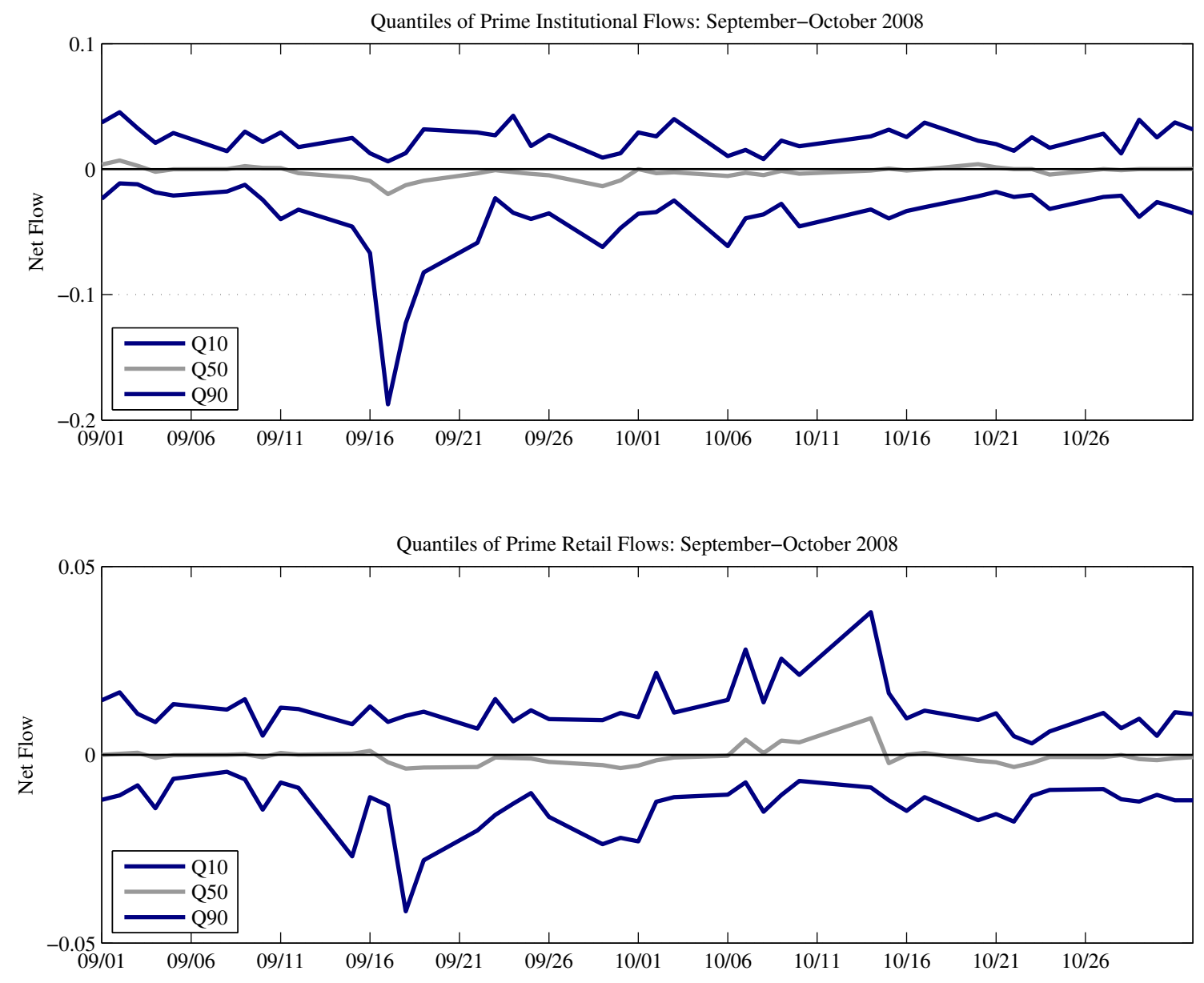

Figure 3: Quantiles of Daily Flow Distributions by Category in September-October 2008 (in \%)

This figure plots the 10th, 50th, and 90th quantiles of complex-category level flows (as a fraction of fund assets) for September-October 2008. The top panel corresponds with Prime Institutional funds, and the bottom panel corresponds with Prime Retail funds. 

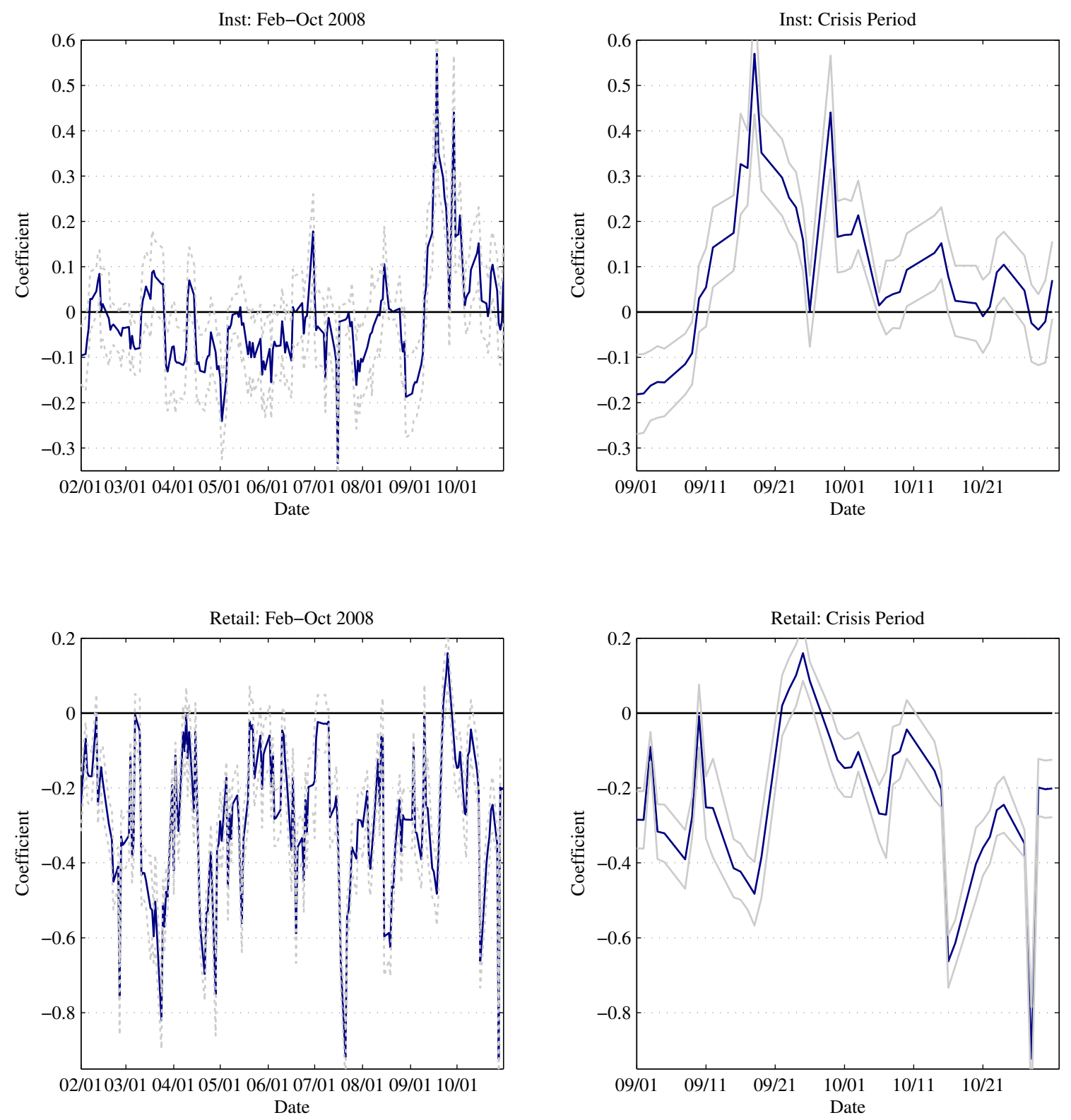

Figure 4: Rolling AR(1) Coefficients for Daily Fund-Level Log Flows

In this figure, we plot coefficient estimates based on panel regressions of the form

$$
y_{i t}=\alpha_{t}+\phi y_{i t-1}+\varepsilon_{i t},
$$

where $y_{i t}=\left(T N A_{i t}-T N A_{i t-1}\right) / T N A_{i t-1}$ is the estimated flow rate for fund $i$ on day $t$. The persistence measure, $\phi$, is obtained using a five-day rolling estimation window. $95 \%$ confidence intervals using robust standard errors are given by lighter lines. The top panel shows the coefficient estimates for Prime Institutional funds, while the bottom panel corresponds with Prime Retail funds. The right panel focuses on September-October 2008. 

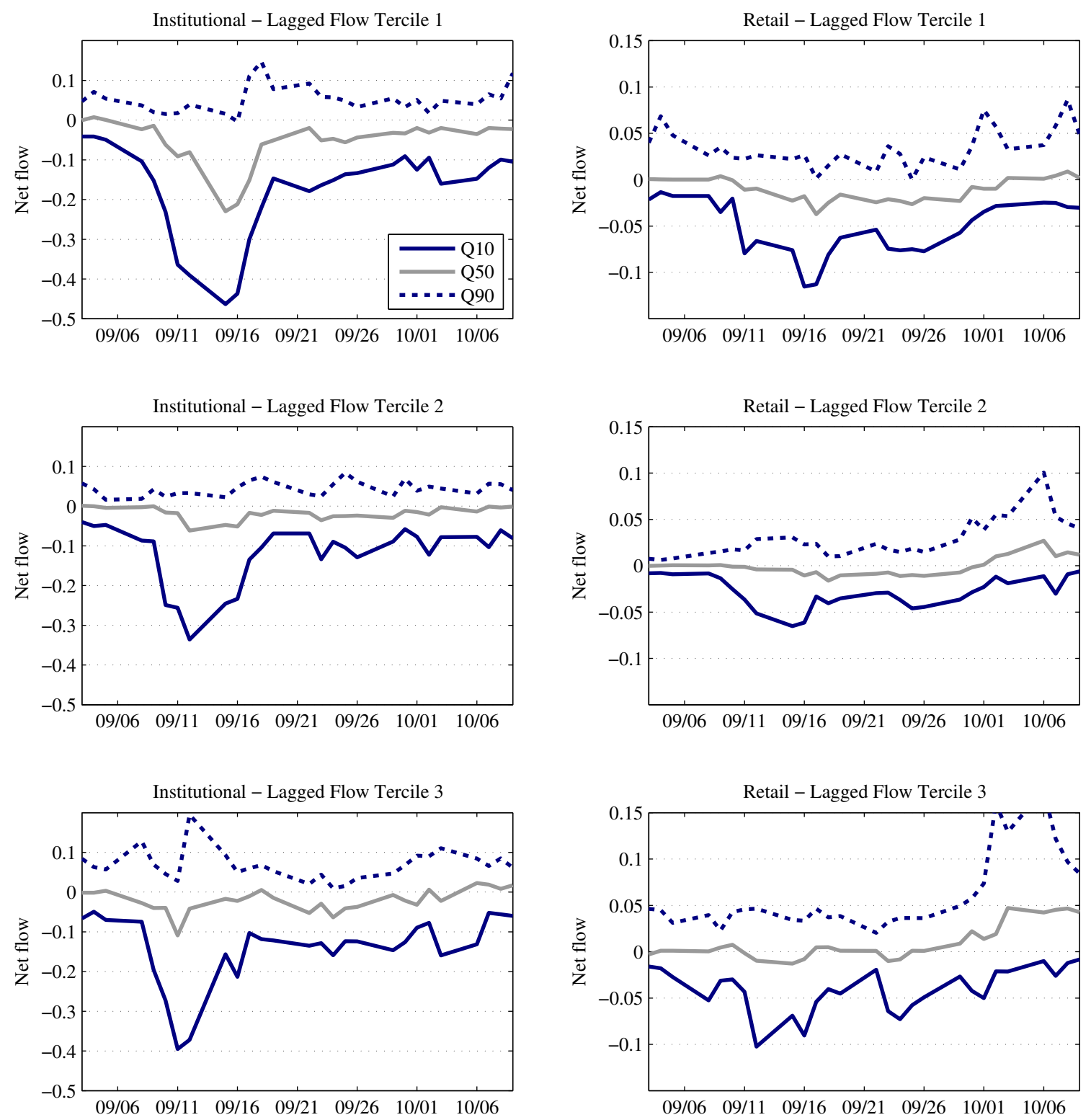

Figure 5: Quantiles of the Weekly Outflow Distribution for Terciles Formed on Lagged Outflows (in \%)

For each date, funds are sorted into terciles according to lagged flows (as a $\%$ of fund assets). We report the $10^{t h}, 50^{t h}$, and $90^{t h}$ quantiles of the subsequent 1-week flow distribution within each tercile. The left column corresponds to Prime Institutional funds, and the right column corresponds to Prime Retail funds 

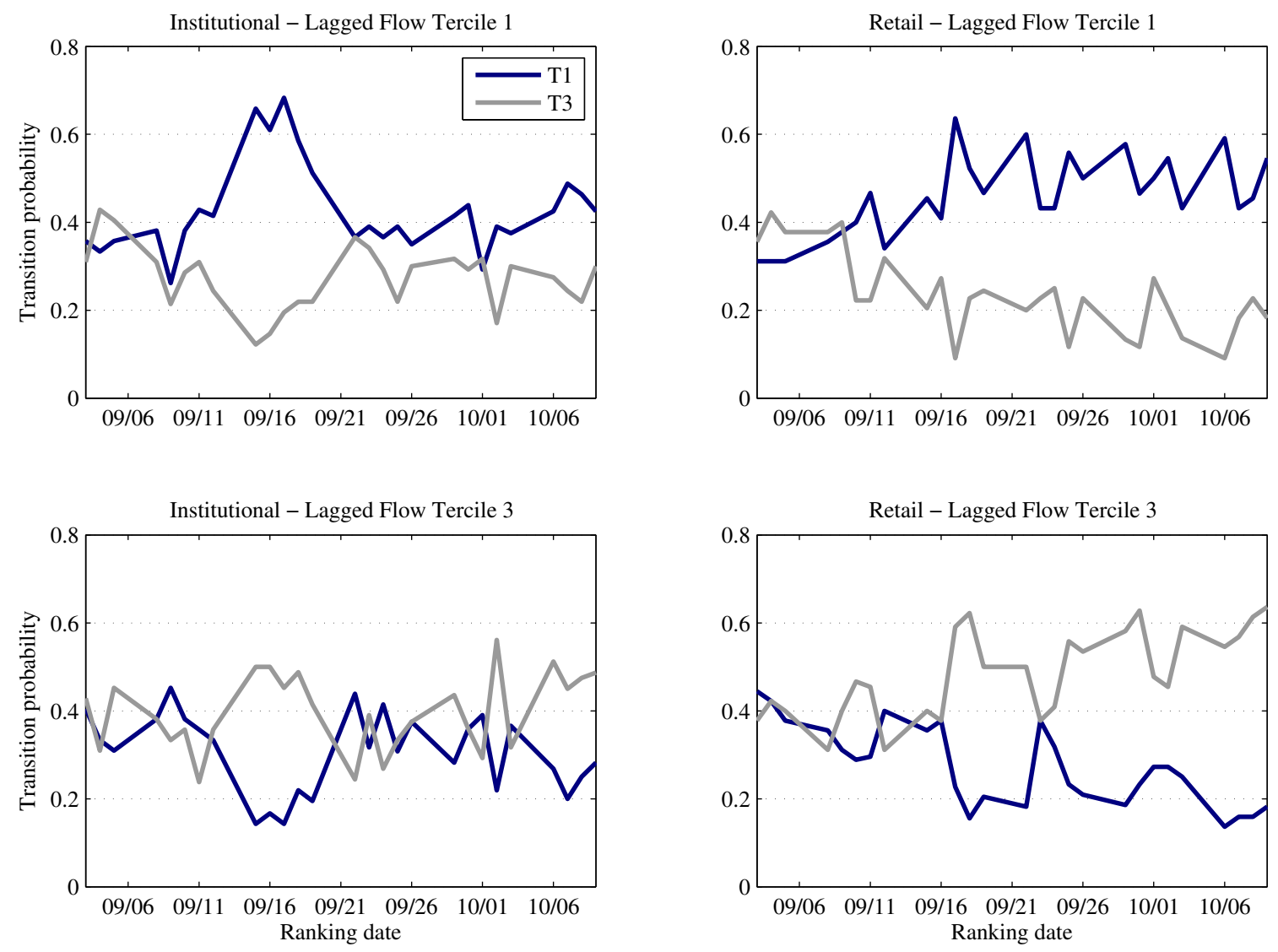

Figure 6: Probability of a Fund Being in the Top/Bottom Tercile of the Weekly Flow Distribution Given Tercile of Previous Day Flows During the Period Surrounding the Crisis Week

For each date, funds are sorted into terciles according to lagged flows (as a \% of fund assets). For each bin, we report the fraction of funds which fall into the bottom/top tercile when ranked by subsequent 1-week flows. The left column corresponds to Prime Institutional funds, and the right column corresponds to Prime Retail funds 
AVGYIELD Bottom Tercile

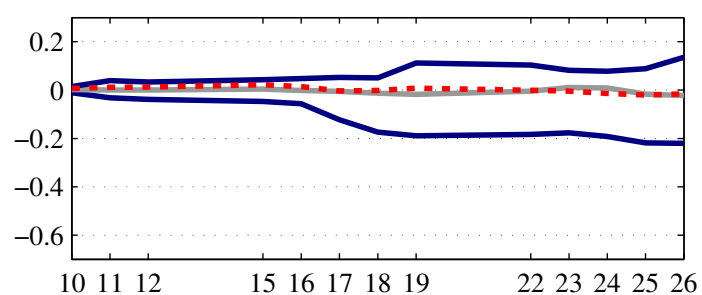

EXPR Bottom Tercile

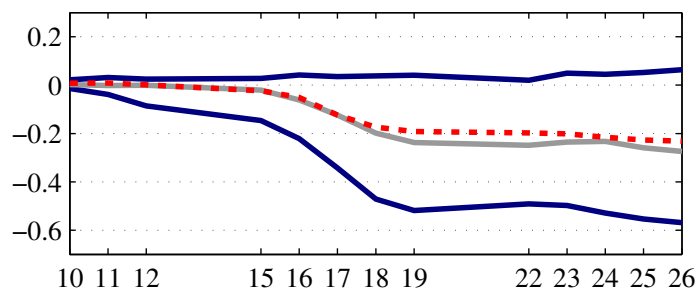

FLOWSTDEV Bottom Tercile

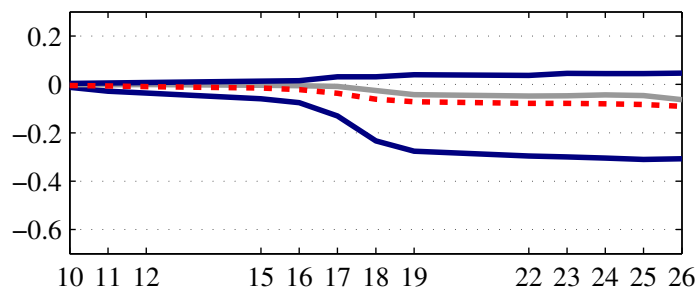

PIPERC Bottom Tercile

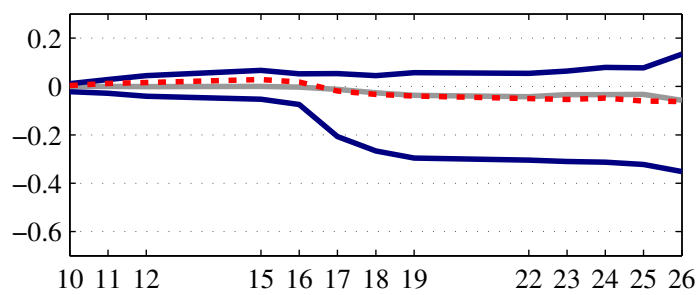

LOGTNA Bottom Tercile

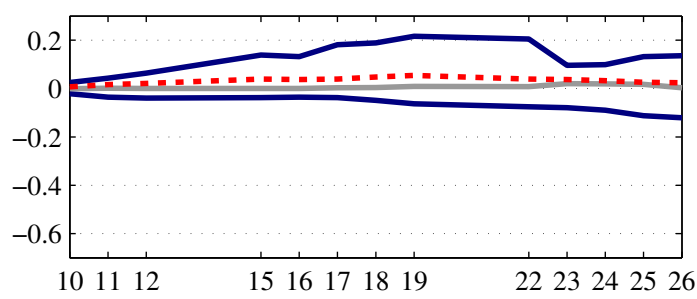

AVGYIELD Top Tercile
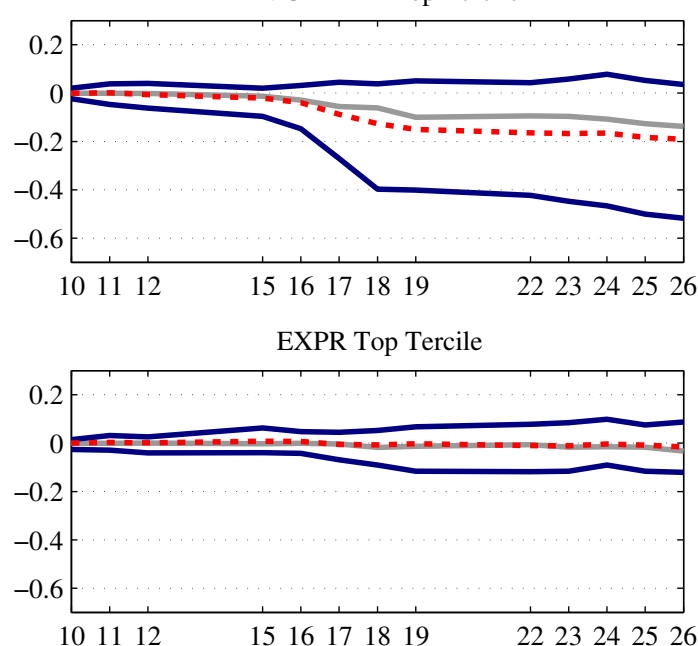

FLOWSTDEV Top Tercile

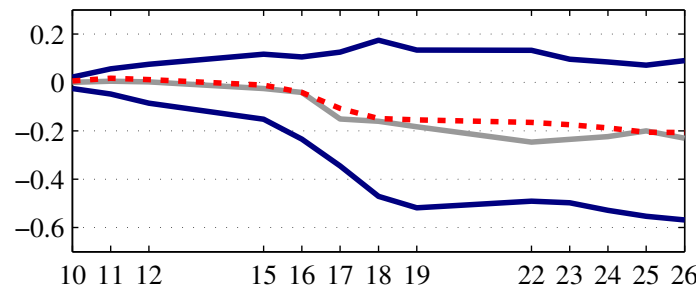

PIPERC Top Tercile

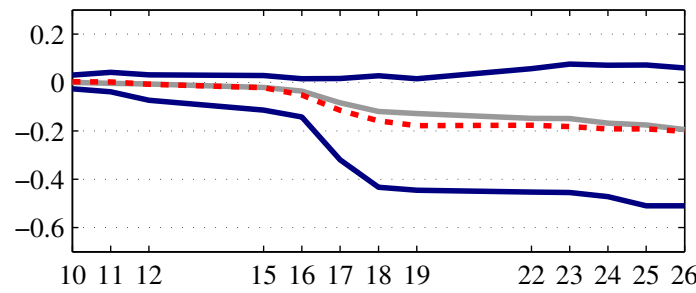

LOGTNA Top Tercile

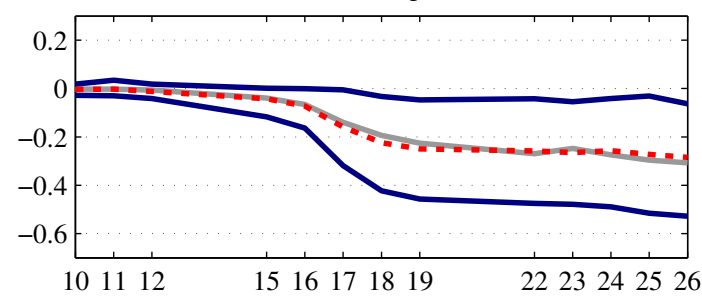

Figure 7: Quantiles of Fund-level Cumulative Flows for Terciles of Funds Ranked by Characteristics Prime Institutional Funds During the Period Surrounding the Crisis Week (in \%)

For each date, funds are sorted into terciles based on a given characteristic. For the top and bottom terciles, we report the 10th, 50th, and 90th quantiles of the cumulative flow distributions (solid lines) as a percentage of initial period assets. Equal-weighted averages are given by dashed lines. Horizontal axis plots the day in September 2008. 
AVGYIELD Bottom Tercile

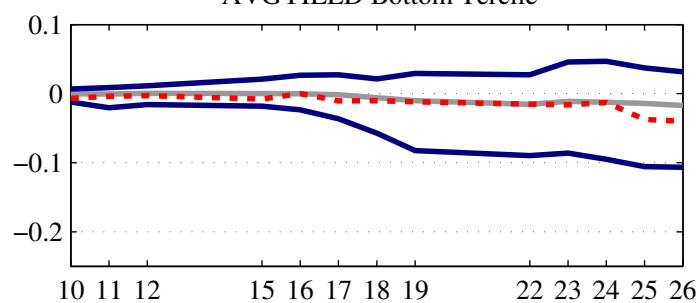

EXPR Bottom Tercile

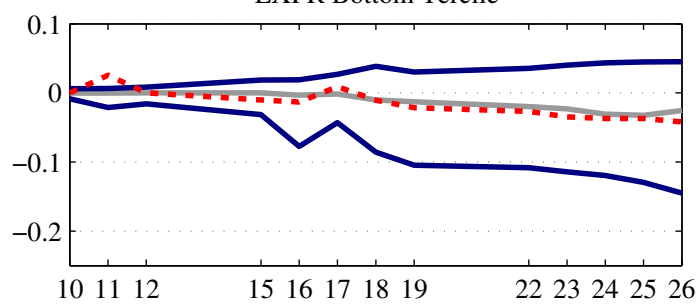

FLOWSTDEV Bottom Tercile

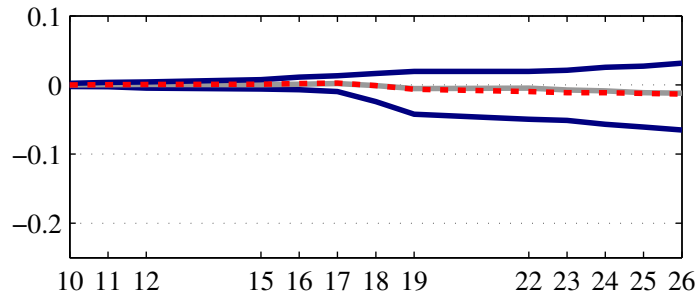

PIPERC Bottom Tercile

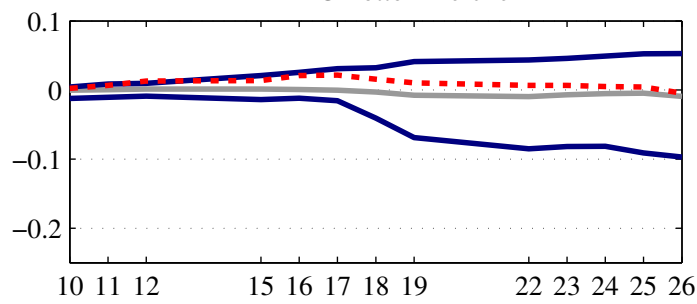

LOGTNA Bottom Tercile

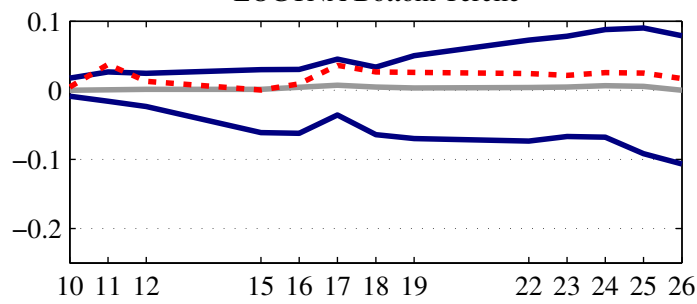

AVGYIELD Top Tercile
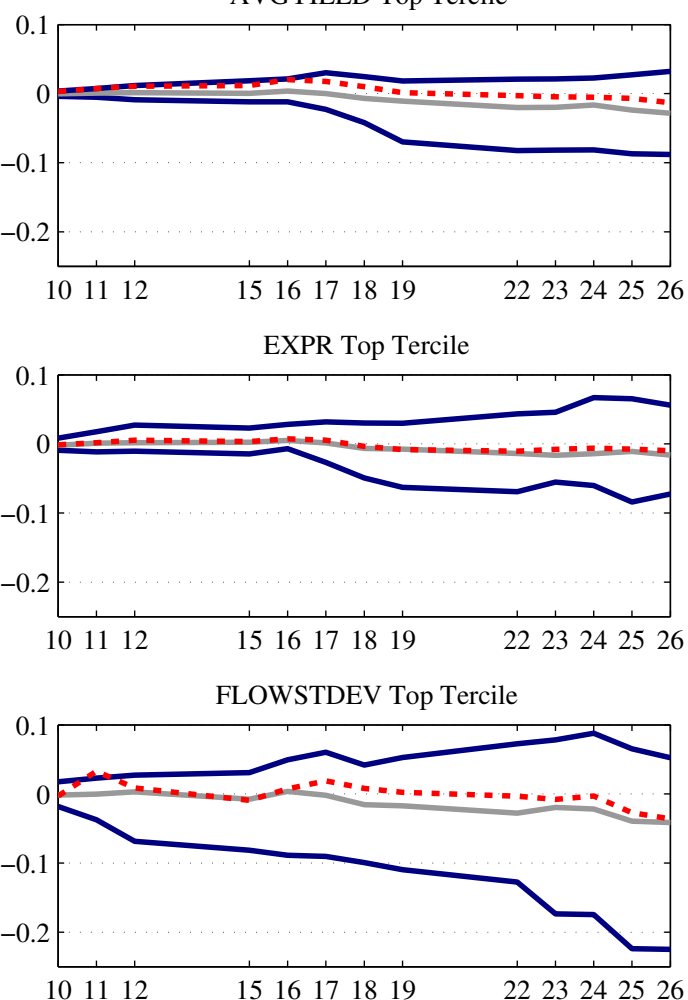

PIPERC Top Tercile
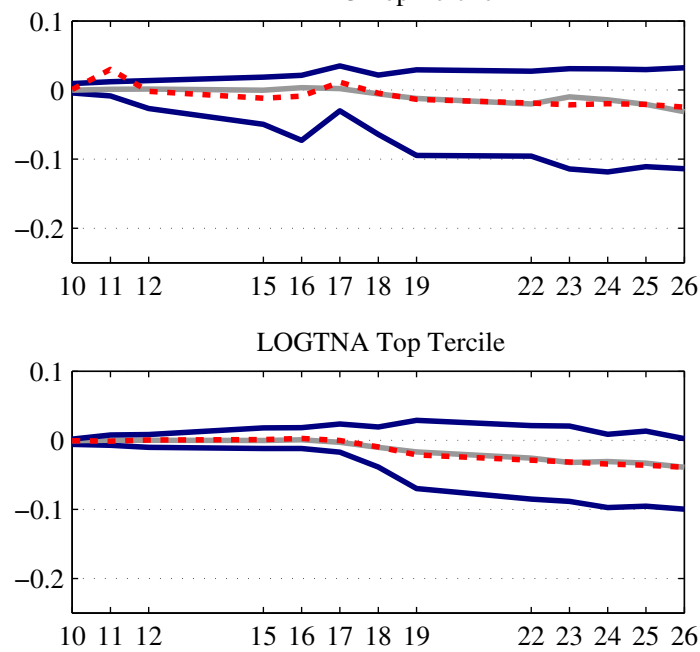

Figure 8: Quantiles of Fund-level Cumulative Flows for Terciles of Funds Ranked by Characteristics Prime Retail Funds During the Period Surrounding the Crisis Week (in \%)

For each date, funds are sorted into terciles based on a given characteristic. For the top and bottom terciles, we report the 10th, 50th, and 90th quantiles of the cumulative flow distributions (solid lines) as a percentage of initial period assets. Equal-weighted averages are given by dashed lines. Horizontal axis plots the day in September 2008. 

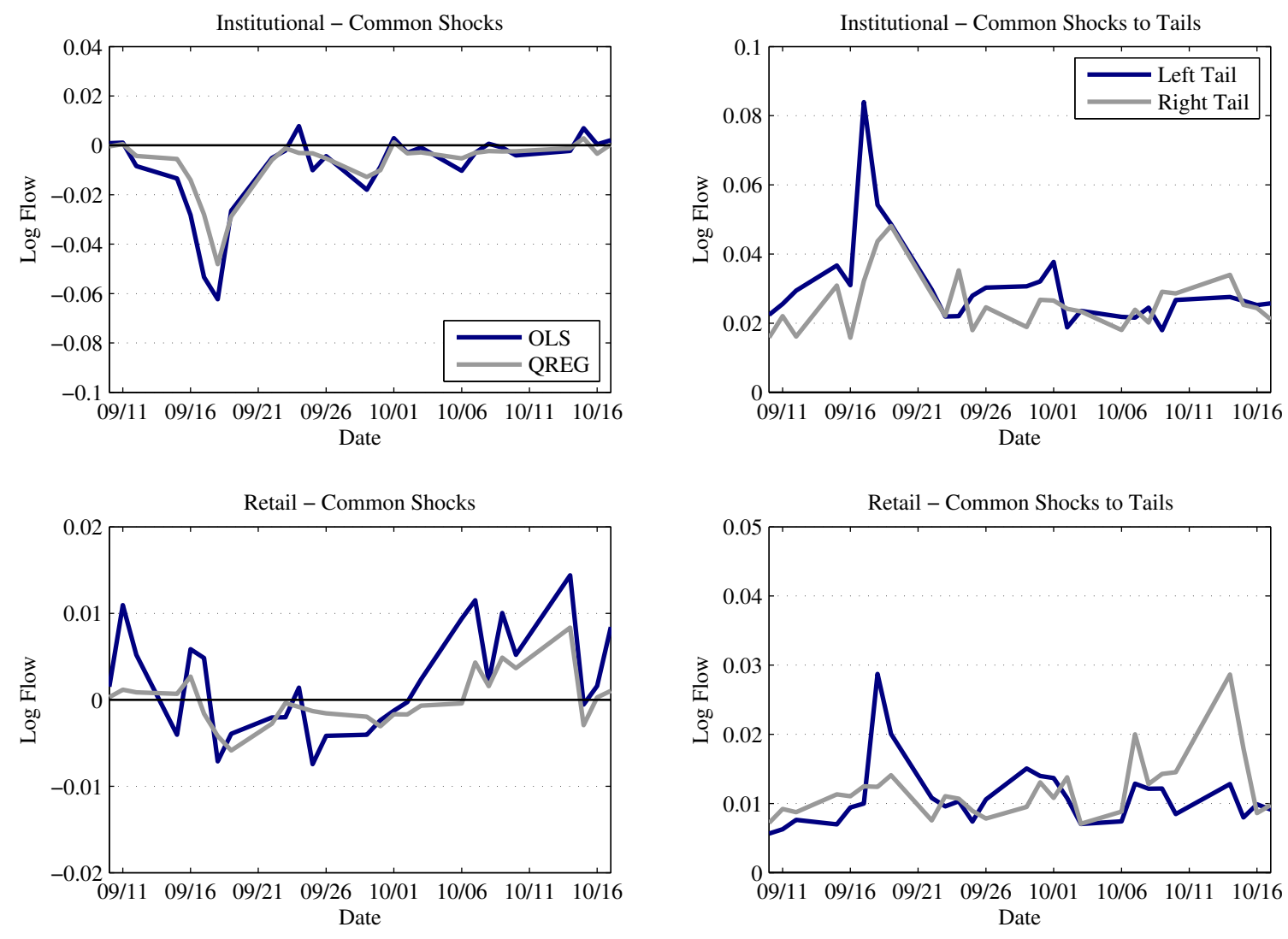

Figure 9: Common shocks from panel regressions

This figure plots the shocks (i.e. time dummies) from the panel OLS and quantile regressions in Tables 5-7. The left panel shows the shocks which affect the central location of the distribution of fund flows, $\xi_{0, t}$, for the OLS regressions and quantile regressions, respectively. The right panel shows the common shocks to the left and right tails, $\exp \left(\xi_{1, t}\right)$ and $\exp \left(\xi_{2, t}\right)$, from the quantile regression models in Tables 6-7, which have no analog in the OLS model. The shock to the left tail, $\exp \left(\xi_{1, t}\right)$, is normalized so that it equals distance between the median and the 10th percentile of the flow distribution for a fund which had a lagged flow equal to the category average and other variables equal to the cross-sectional mean for funds in the same category. The shock to the right tail, $\exp \left(\xi_{2, t}\right)$, is normalized to equal the distance between the 90th percentile and the median for a fund with the same characteristics. 

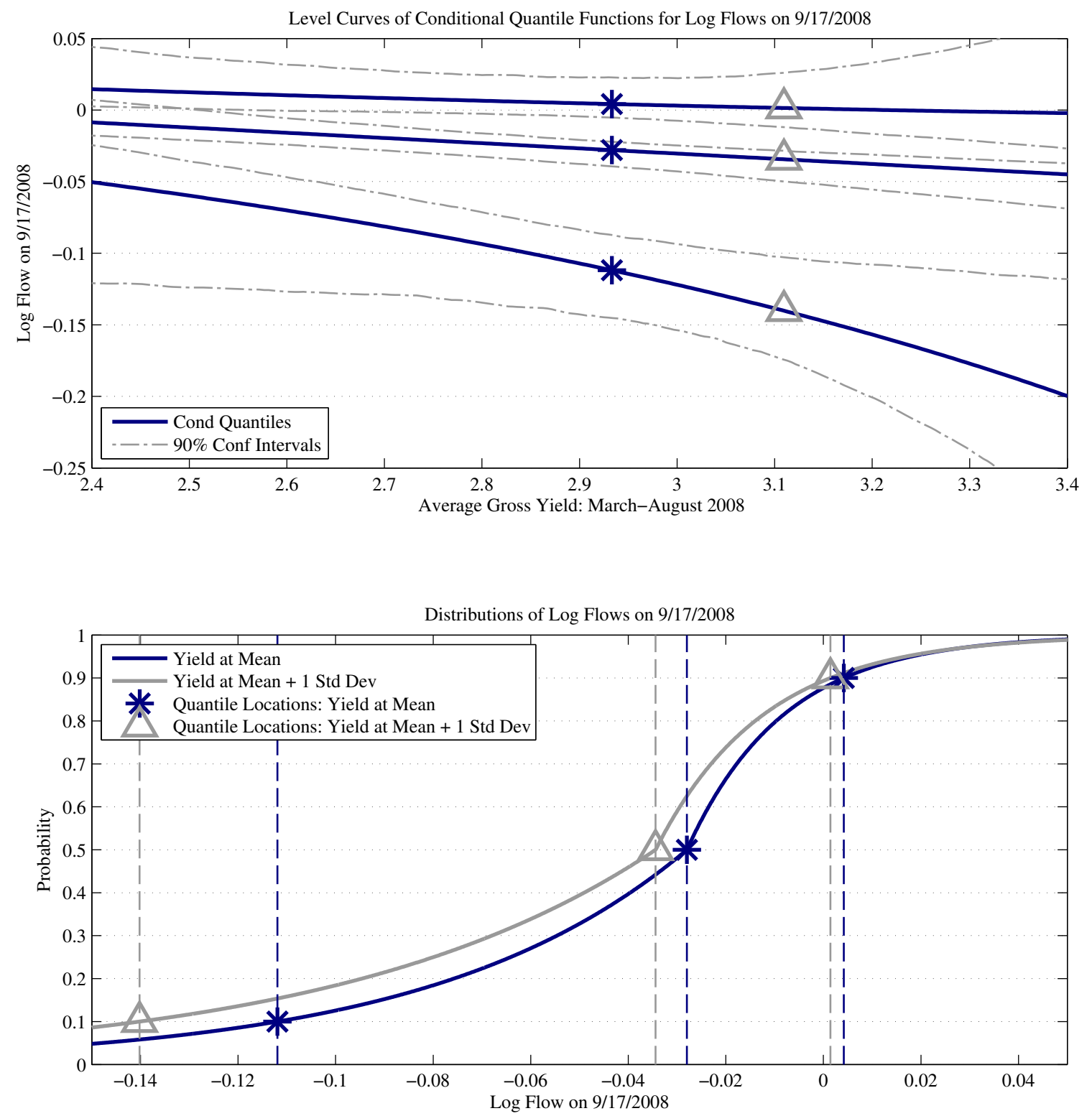

Figure 10: Marginal Effects of Average Yield Variable on Log Flow Distribution for 9/17/2008 - Prime Institutional Funds

The top panel plots the effect of changing the variable AVGYIELD on the 10th, 50th, and 90th conditional quantiles of the flow distribution for Prime Institutional funds on 9/17/2008. Lagged flows are held constant at the category-level flow and all other variables are held constant at their cross-sectional averages. 90\% bootstrapped confidence intervals are plotted by light dashed lines. Stars mark the location of the cross-sectional average value of AVGY IELD (about 2.95\% per annum), and triangles add 1 standard deviation (about 15 $\mathrm{bp)}$ to this value. The bottom panel plots the conditional distribution functions of flows at these two points, where we interpolate between quantiles by assuming that $\eta_{i, t}$, as defined in the text, is drawn from an exponential distribution. This distributional assumption is not imposed in the estimation procedure. As above, stars and triangles (along with dashed lines) mark the locations of the conditional quantiles for each value of $A V G Y I E L D$. 

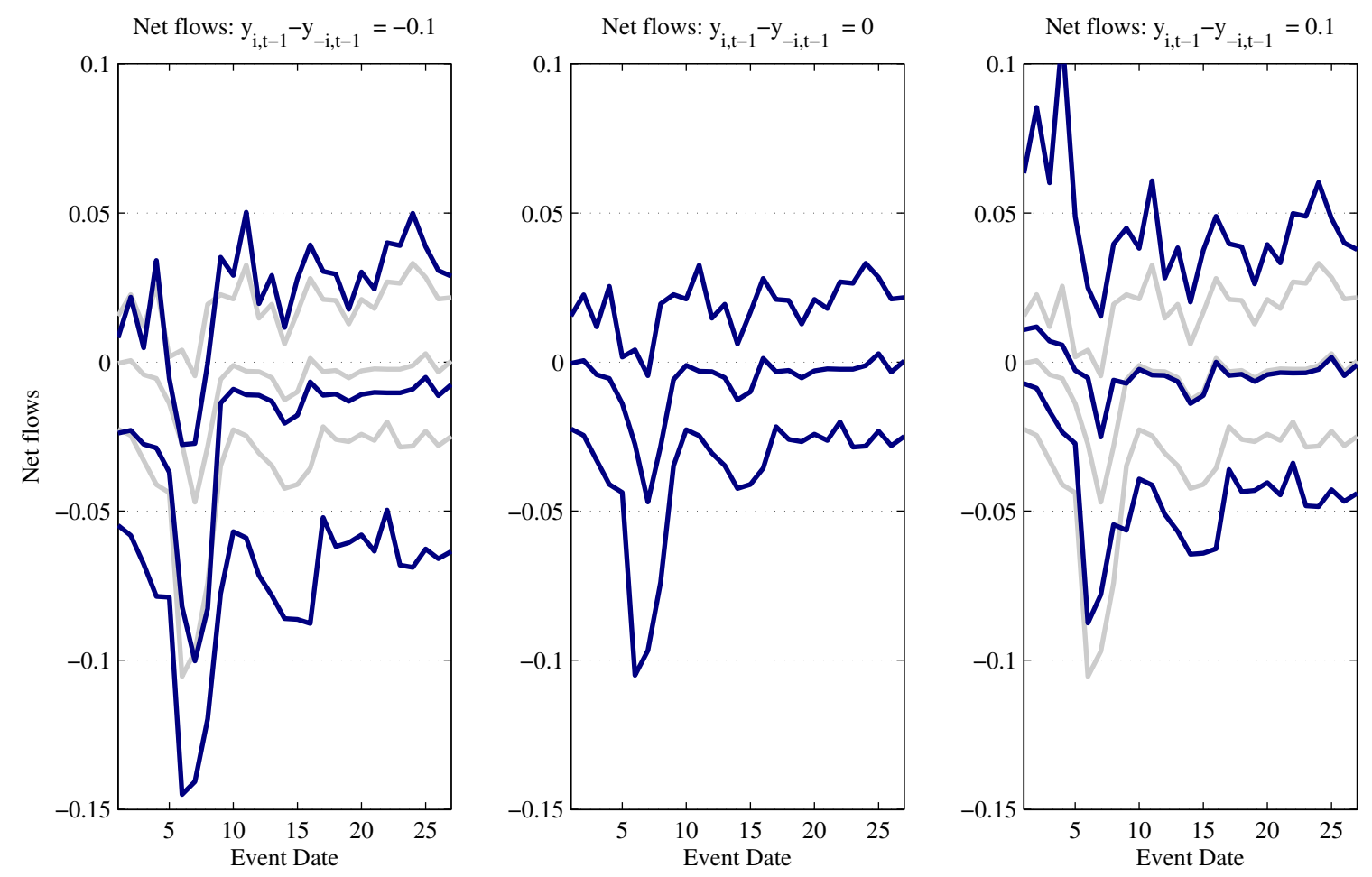

Figure 11: Impact of lagged flows for Prime Institutional funds in baseline specification

The top panel plots the effect of changing $y_{i, t-1}-\bar{y}_{t-1}$ on the 10th, 50th, and 90th conditional quantiles of the flow distribution for Prime Institutional funds for each date in our sample period. All other variables are held constant at their cross-sectional averages. The picture from the center panel, where $y_{i, t-1}=\bar{y}_{t-1}$, is superimposed in the left and right panels in light gray for ease of comparison. 


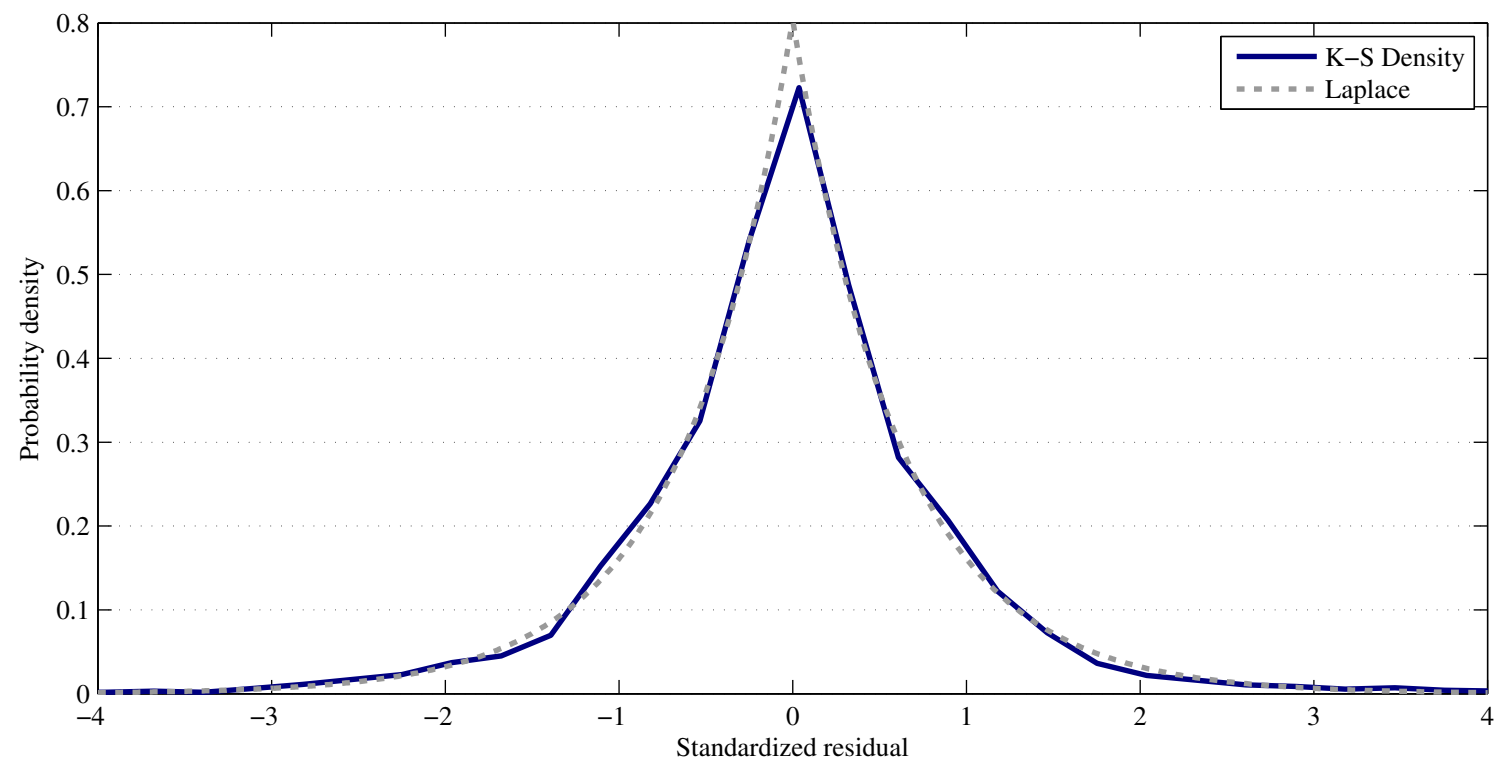

Figure 12: Standardized residual density from baseline model - Institutional funds

This figure plots the empirical distribution of the standardized residuals from the model in Table $6, \hat{\eta}_{i, t}$, which is generated using a kernel smoother. The dashed line plots the density of a Laplace-distributed random variable which has been normalized to satisfy the conditional quantile restriction which is assumed when estimating the model. 

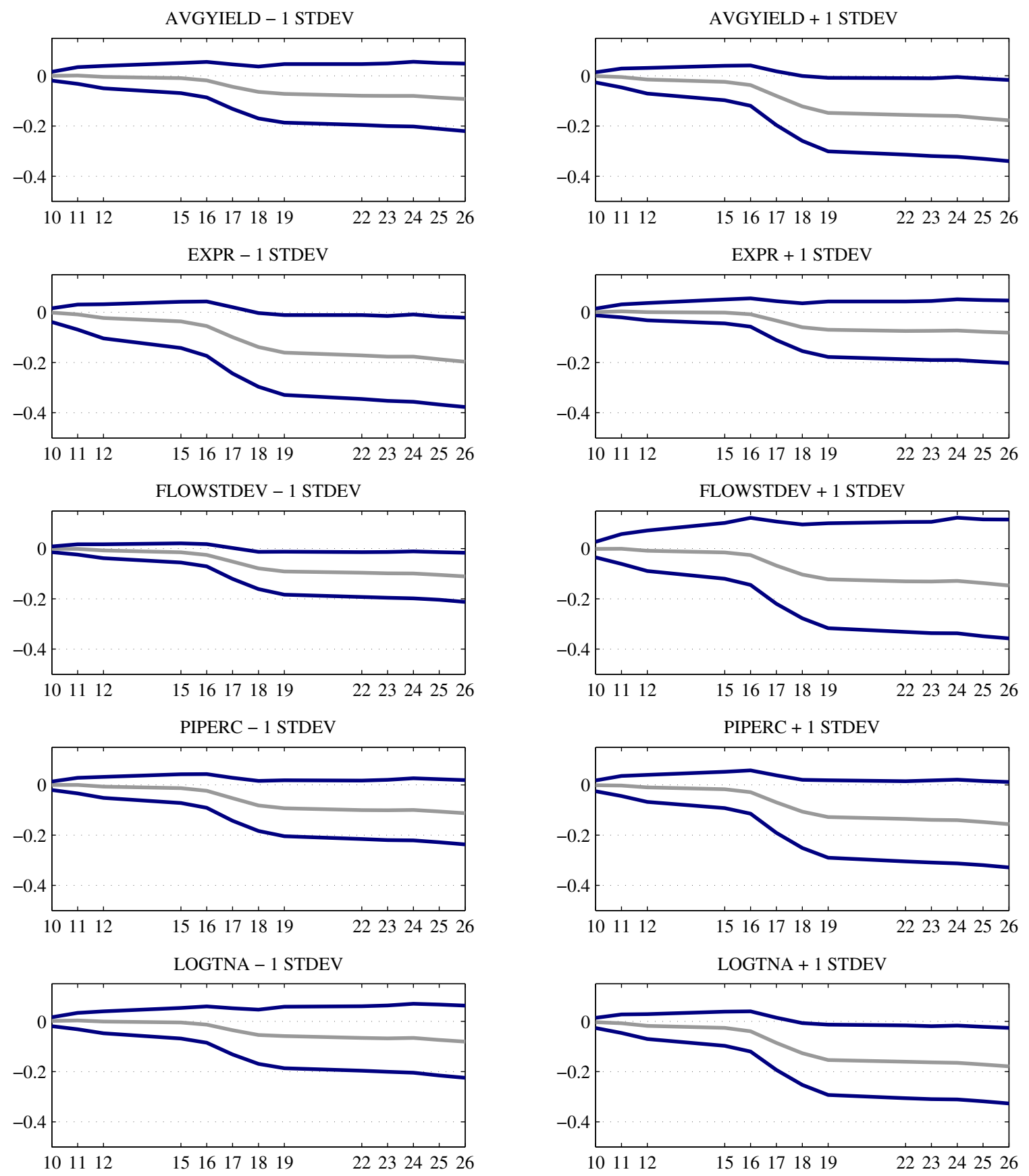

Figure 13: Impact of explanatory variables on multi-period flow distributions - Institutional funds

This figure shows the impact of explanatory variables on quantiles of multi-period cumulative flow distributions (as a \% of initial assets). The lines plot the 10th, 50th, and 90th quantiles of the cumulative flow distributions, respectively. We fix each of the explanatory variables at its average plus or minus one standard deviation. The initial value of lagged flows is assumed to be equal to the category average, and all other variables are fixed at their averages. We estimate the quantiles by drawing shocks from the Laplace distribution and using the recursive definition of the dependent variable to simulate 10,000 sample paths for each set of conditioning variables. 